\title{
Paying Patients: Legal and Ethical Dimensions
}

\author{
Govind Persad ${ }^{1}$
}

\author{
20 YALE J. L. \& TECH. 177 (2018)
}

This Article explores the implications for medical care of a debate that is more familiar in the law and ethics of human subjects research: whether people should be paid to receive or decline medical interventions, or to reach certain health objectives. It examines the legal and ethical issues such payments raise, and considers various actors who might make such payments, including governments, employers, insurers, care providers, and private parties. It argues for two interrelated conclusions: first, that these payments should not be subject to blanket normative condemnation, and, second, that payments made in different settings and contexts frequently share underlying commonalities, which suggests categorizing them according to these commonalities. We should move from a "siloed" legal and normative landscape, where discussions of payments to patients in one context are isolated from similar discussions in other contexts, to a landscape where payments are evaluated and categorized more systematically. The categories along which payments should be evaluated include who the payer is, what purpose the payment serves, and who the payment affects.

In Part I, I identify and present four categories of payments to patients. These include value-based insurance designs in which insurers offer patients a share of the savings realized when they choose cheaper medications; providers paying patients to adhere to treatment regimens; and private parties paying others to make health decisions such as avoiding pregnancy.

In Part II, I examine the normative issues raised by these payments. I argue that the risk of exploitation or undue psychological pressure is low, but that we should be more concerned about ways in which the payments might change relationships between payers and payees or might harm the

Assistant Professor, Department of Health Policy and Management, Johns Hopkins University. J.D., Stanford Law School; Ph.D., Stanford University. I am grateful to colleagues at the Berman Institute of Bioethics, to Kristin Madison and others at the 2016 Health Law Professors Conference, and to Christina Ho and John Jacobi for their detailed comments at a presentation of these ideas at the 2017 Mid-Atlantic Health Law Works-in-Progress Retreat, as well as to other retreat attendees for their feedback. I am also grateful to Alan Wertheimer, Zeke Emanuel, Christine Grady, Harald Schmidt, and Richard Yetter Chappell for discussion of related ideas. 
interests of third parties. In developing this analysis, I draw on work in the ethics of human subjects research.

In Part III, I use the ethical analysis developed in Part II to develop normative frameworks for the evaluation of payments to patients. These frameworks identify and differentiate the responsibilities of different actors in the health care system. In doing so, these frameworks draw from and build on theories of distributive fairness. They also draw from accounts of professional and business ethics that prescribe specific responsibilities for professionals.

Finally, in Part IV, I examine how these normative frameworks would bear on the legal issues that payments to patients raise. These include whether the payments are subject to taxation or might affect recipients' eligibility for need-based benefits; whether they are consistent with antidiscrimination law; and whether they violate anti-kickback statutes or regulations. 
TABLE OF CONTENTS

INTRODUCTION ........................................................ 180

I. PAYing PATIEnTS: FaCtual Scenarios ...................... 181

A. Paying for Use ....................................................... 182

1. Coupons and Discounts .............................. 182

2. Payments for Use ....................................... 183

B. Paying for Adherence .......................................... 184

1. Mental Health Treatment............................ 186

2. Substance Use Cessation ............................. 187

3. Communicable Disease Treatment ................ 188

4. Other Examples............................................ 189

C. Paying for Cost-Effectiveness or Lower Cost ........... 189

D. Paying for Health Decisions and Outcomes ............. 192

1. Paying for Health Improvement.................... 192

2. Paying for Other Health Choices.................... 193

II. PAytng PATIENTS: ETHICAL ISSUES ........................... 194

A. Concerns About Deliberative Autonomy ................. 195

1. Coercion ..................................................... 195

2. Undue Inducement...................................... 197

3. Deliberative Diversion and Deliberative Insulation.................................................... 199

B. Other Patient-Focused Concerns............................ 204

1. Exploitation ............................................ 204

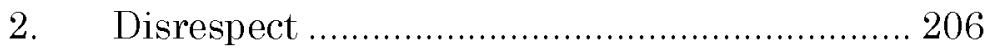

3. Discrimination .............................................. 207

C. Commodification Concerns .................................. 210

D. Societal Concerns .................................................. 214

1. Absolute and Comparative Deservingness ..... 214

2. Effects on Others' Options ............................ 217

3. Creating Corrosive Disadvantages................ 218

4. Inefficiency .................................................... 219

III. PAYing PATIENTS: NORMative Categories AND

FRAMEWORKS.............................................................. 219

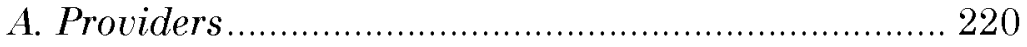

B. Insurers and Hospitals ........................................ 222

C. Governments ........................................................ 223

D. Private Individuals ........................................... 224

IV. Paying Patients: Legal Issues ........................... 225

A. Taxability and Program Eligibility ...................... 225

B. Antidiscrimination Law........................................ 226

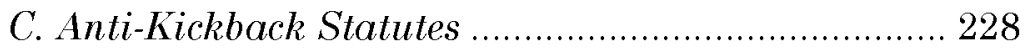

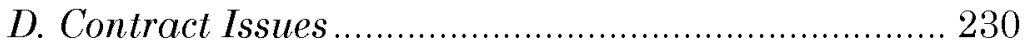

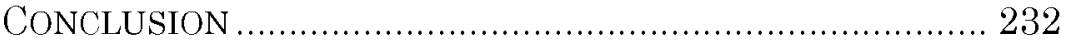




\section{INTRODUCTION}

Debate about whether subjects should be paid to participate in medical research is a longstanding part of the law and ethics of human subjects research protection. Some have raised concerns about exploitation of subjects or psychological pressure. Others have worried that payments undermine public-spiritedness or jeopardize relationships between subjects and researchers. Payments in medical care, such as payments to patients receiving clinical care or to insured individuals within a health care system, raise similar questions. Such payments are already being made in some contexts, and their importance is likely to increase in a regulatory environment like that of the United States, where universal health care is not publicly funded (and not likely to be) and where private parties accordingly have a financial stake in other people's health choices.

This Article will examine the legal and ethical issues raised by paying patients to receive or decline medical interventions, or to reach certain health objectives. It will consider various actors who might make such payments, including governments, employers, insurers, care providers, and private parties. It will also consider some legal issues these payments raise. Ultimately, it will argue for two interrelated conclusions: first, that these payments should not be subject to blanket normative condemnation and, second, that payments made in different settings and contexts frequently share underlying commonalities, which suggests categorizing them according to these commonalities. We should move from a "siloed" legal and normative landscape, where discussions of payments to patients in one context are isolated from similar discussions in other contexts, to a landscape where payments are evaluated and categorized more systematically. The categories along which payments should be evaluated include who the payer is, what purpose the payment serves, and who the payment affects.

In Part I, I identify and present four categories of payments to patients. These include value-based insurance designs in which insurers offer patients a share of the savings realized when they choose cheaper medications; providers paying patients to adhere to treatment regimens; and private parties paying others to make health decisions such as avoiding pregnancy.

In Part II, I examine the normative issues raised by these payments. I argue that the risk of exploitation or undue psychological pressure is low, but that we should be more concerned about ways in which the payments might change relationships between payers and payees or might harm the interests of third parties. In developing this analysis, I draw on 
work in the ethics of human subjects research.

In Part III, I use the ethical analysis developed in Part II to develop normative frameworks for the evaluation of payments to patients. These frameworks identify and differentiate the responsibilities of different actors in the health care system. In doing so, these frameworks draw from and build on theories of distributive fairness. They also draw from accounts of professional and business ethics that prescribe specific responsibilities for professionals.

Finally, in Part IV, I examine how these normative frameworks would bear on the legal issues that payments to patients raise. These include whether the payments are subject to taxation or might affect recipients' eligibility for need-based benefits; whether they are consistent with antidiscrimination law; and whether they violate anti-kickback statutes or regulations.

\section{Paying Patients: Factual Scenarios}

Many actors pay individuals to make medical choices or to achieve specific health outcomes, or have proposed paying individuals to do so. These actors include agencies within federal and state government (such as Medicare, Medicaid, and the Veterans' Administration, as well as state and federal employee health plans and various state and federal public health programs); non-governmental organizations; health insurers; hospitals and health care providers; and other private parties.

Payments to patients are only one of the possible financial incentives that might influence patients' choices. Discounted medical care, such as charity care offered by hospitals or providers, can also affect patients' choices. So can differential pricing, where patients are charged for care according to their status as insured or uninsured, or according to their ability to pay. Indeed, the simple fact that medical care costs money already makes financial considerations relevant to patients' choices, because it presents trade-offs between medical care and other goods. However, payments to patients use incentives as a carrot - to encourage a choice-rather than as a stick that imposes a penalty on certain choices.

In this Part, I review four potential contexts in which these actors may choose to pay patients: (a) to incentivize patients' use of specific medical interventions that are profitable for providers; (b) to promote adherence to medical treatment recommendations, such as pharmaceutical dosing schedules or regular follow-up appointments; (c) to incentivize the choice of cheaper or more cost-effective interventions; and (d) in exchange for their achieving health outcomes, including both 
outcomes generally regarded as desirable (such as smoking cessation) and more controversial outcomes (such as pregnancy avoidance or carrying a pregnancy to term).

\section{A. Paying for Use}

In this Section, I discuss the use of coupons and discounts to incentivize the use of medical care, as well as direct payments to users of medical care.

\section{Coupons and Discounts}

Actors in the medical care system who gain financially from the use of medical care, such as drug or device vendors, could pay patients to purchase certain forms of health care. These payments take advantage of the fact that insured patients do not bear the full cost of medical care use, which means that a seller who pays patients to use a specific product can also capture some of an insurer's spending. The use of coupons for prescription drugs is a prominent example. As Joseph Ross and Aaron Kesselheim observe, by offering coupons that lower the out-of-pocket cost of a drug, pharmaceutical companies are able to direct insurer spending toward specific drugs:

On a population level, drug coupons undermine the tiered-formulary system that commercial insurers have implemented to limit prescriptiondrug spending. When patients use coupons to obtain brand-name medications, their out-ofpocket spending is reduced. But insurers must still pay the higher cost of the medication to the manufacturer. The more that patients use drug coupons to obtain brand-name medications when lower-cost alternatives are available, the more expenses will rise for their insurers. ${ }^{2}$

Ross and Kesselheim note that coupons bypass the cost-sharing arrangements that insurers or other payers agree to with patients (such as value-based insurance arrangements), and have been challenged in court as illegal kickbacks. ${ }^{3}$ In particular, because the federal anti-kickback statute "prohibits knowingly paying a party to stimulate business that is in turn paid for by a federal health care program," "federal policy currently prohibits the use of coupons by patients in publicly subsidized drug-insurance programs such as Medicare and

2 Joseph S. Ross \& Aaron S. Kesselheim, Prescription-Drug Coupons-No Such Thing as a Free Lunch, 369 NEw ENGL. J. MED. 1188, 1189 (2013).

$3 \quad I d$. 
Medicaid." 4

\section{Payments for Use}

Moving from coupons to direct payments, there are several examples where medical care providers go beyond discounting the cost of care to paying patients outright to use an intervention. As Kesselheim and Ross note, this practice violates federal law when it involves payments to Medicaid or Medicare patients to use services paid for by those programs. ${ }^{5}$

Examples of these positive payments are described in case law, including payments to patients who submitted their Medicare claims or filled prescriptions through certain pharmacies, ${ }^{6}$ payments to attend psychiatric hospitalization programs, ${ }^{7}$ payments to visit a clinic, ${ }^{8}$ and payments to use a specific hospital. ${ }^{9}$ A recent New York case provides a representative example of such arrangements when it discusses "a scheme to defraud the Medicaid program by utilizing paid recruiters, known as 'flyer guys,' to solicit patients to receive dental services at the clinic in exchange for some form of remuneration." ${ }^{10}$ The Office of the Inspector General has advised that payments to patients who are insured through federal programs may violate the anti-kickback law, which prohibits

Id.

42 U.S.C § 1320a-7b (2012); see also Alan Bloom \& Charles B. Oppenheim, Fraud in Managed Care: Old Wine in New Bottles, 18 WhitTIER L. Rev. 13, 20 (1996): ("[T]here is also a fraud and abuse issue when a provider makes payments to patients to induce the patients to use that provider. The issue is raised when managed care organizations provide more benefits to patients or reduce the copayments as an inducement for the Medicare beneficiaries to enroll with that managed care organization.").

6 United States v. Medina, 485 F.3d 1291, 1295 (11th Cir. 2007) ("Kickbacks were paid to entice patients to submit their medicare [sic] claims through Ocean and/or United. A number of patient recruiters testified that they would bring patients who needed to fill prescriptions to Ocean or United in exchange for $50 \%$ of the profits made after submitting the claim to Medicare. The recruiter would then share their $50 \%$ with the patient.").

7 United States v. Hunter, 628 F. App'x 904, 906 (5th Cir. 2015) ("Although Medicare allows facilities to advertise their services, they may not pay patients to attend a PHP program.").

8 United States v. Umawa Oke Imo, 739 F.3d 226, 231 (5th Cir. 2014) ("CNS only accepted patients with Medicare or Medicaid. . . CNS . . paid patients whenever they visited the clinic for an initial assessment and any subsequent reassessment.").

9 United States v. Bainbridge Mgmt., L.P., No. 01 CR 469-1, 2002 WL 31006135 , at ${ }^{*} 1$ (N.D. Ill. Sept. 5, 2002) (describing an indictment that "alleges defendants. . generated hospital admissions through cash payments and benefits to patients").

10 Kim v. Bd. of Regents of State of N.Y., 4 N.Y.S.3d 369, 370 (N.Y. App. Div. 2015). 
[a]ny payment, including cash or other benefit, given to a patient, provider, or supplier for changing a prescription, or recommending or requesting such a change, from one product to another, unless the payment is fully consistent with a "safe harbor" regulation, or other federal provision governing the reporting of prescription drug prices. ${ }^{11}$

In another example, a False Claims Act suit against Kmart for offering discount coupons and gift cards to federal health care beneficiaries survived a motion for summary judgment. ${ }^{12}$ In the United Kingdom, where treatment in public hospitals is covered at government expense, a private health insurer paid its patients to seek certain procedures in public hospitals rather than private ones and was criticized for doing so. ${ }^{13} \mathrm{I}$ could not find examples of payments to patients with private insurance described in the case law, perhaps because these arrangements are typically legal and therefore generated no litigation.

Providers of services could also pay patients for reasons other than capturing insurers' spending. Providers could pay patients who agree to receive a procedure from a trainee physician or to receive a procedure at a time when demand is lower. A new provider might pay patients to use its services in order to build goodwill or raise its public profile, just as a nonhealth business might give away free products.

\section{B. Paying for Adherence}

A patient's medical outcomes depend not only on whether medical professionals are able to accurately diagnose the symptoms and recommend a course of treatment, but also on

Thomas N. Bulleit, Jr. \& Joan H. Krause, Kickbacks, Courtesies or CostEffectiveness?: Application of the Medicare Antikickback Law to the Marketing and Promotional Practices of Drug and Medical Device Manufacturers, 54 FOOD \& DRUG L.J. 279, 287 (1999) (quoting Special Fraud Alert on Arrangements for the Provision of Clinical Laboratory Services, 59 Fed. Reg. 65,372 , at 65,376 (Dec. 19, 1994)).

12 United States ex rel. Yarberry v. Sears Holdings Corp., No. 09-CV-588-MJRPMF, 2013 WL 12111729, at * 1 (S.D. Ill. Nov. 20, 2013) (denying a motion for summary judgment on complaint that "Defendants Sears and Kmart violated the federal False Claims Act ('FCA'), as well as the Anti-Kickback Statute (AKS), and parallel state statutes, by offering and paying monetary inducements, such as cash gift cards and/or coupon promotions, to the beneficiaries of Government Healthcare Programs ('GHPs') . . . including Medicare, Medicaid, TRICARE and CHAMPUS, in exchange for beneficiaries filling their prescriptions at Defendants' pharmacies").

13 Gill Plimmer \& Alistair Gray, Insurers Accused of 'Bribing' Patients to Use NHS, Fin. Times (April 1, 2014), http://www.ft.com/content/73b11ed4-b9c111e3-a3ef-00144feabde0 [http:/perma.cc/92UD-HYQ5]. 
whether the patient is adherent or compliant with the course of treatment recommended. Non-adherence can stem from multiple sources, including inconvenience, cost, forgetfulness, or skepticism about a treatment's value. Payments to patients might be expected to increase adherence and potentially generate socially valuable outcomes for at least two reasons:

First, patients may value good medical outcomes, but be subject to psychological frailties that prevent them from attaining those outcomes (in philosophical terms, they are akratic or "weak-willed": they know what they should do, but are unable to do it reliably). Some patients may be addicted to harmful substances or mentally ill. ${ }^{14}$ Even those who are not may engage in hyperbolic discounting-they may give insufficient weight to long-term benefits when deciding what to do. Reliable, short-term financial rewards may help them achieve the outcomes they value.

Second, the value of a given medical outcome to society may be larger than its value to the patient. In this case, a perfectly rational and non-altruistic patient would put less effort into achieving that outcome than would be optimal from a societal perspective. Even given the fact that patients are both somewhat altruistic and only boundedly rational, financial rewards could sometimes shift patients away from a course of behavior that would be individually optimal toward one that would be socially optimal. As Antonio Giufridda and David Torgerson observe,

The consumption of health care is generally sensitive to its price. All things being equal, uptake or compliance will be lower when there is a financial charge than when health care is free to the patient .... [E]ven when free medical care is the alternative, the use of some form of financial inducement increases compliance. ${ }^{15}$

In this Section, I review several examples of payment for adherence. Cases where payment for adherence has been particularly prevalent include (1) mental health treatment, (2) substance use cessation, and (3) treatment of infectious disease. These cases tend to be characterized by one or both of two features: large positive externalities (benefits to society)

14 E.g., Tim Kendall, Paying Patients with Psychosis to Improve Adherence, 347 BMJ 5782 (2013) ("However, when the illness impairs insight, as is common in people with psychoses such as schizophrenia, or leads to an erosion of willpower, as can occur in people who misuse substances, supplementing internal rewards with external incentives deserves serious consideration.").

15 Antonio Giuffrida \& David J. Torgerson, Should We Pay the Patient? Review of Financial Incentives to Enhance Patient Compliance, 315 BMJ 703, 705-06 (1997). 
and/or a tendency for patients to make irrational decisions not to adhere.

\section{Mental Health Treatment}

Payment for adherence has been frequently suggested in the treatment of severe mental illness, such as psychosis. A recent study by Stefan Priebe and co-authors asserts that "observational studies with small samples suggest that financial incentives may . . . improve drug adherence in patients with psychotic disorders," and the study later concludes on the basis of a novel randomized controlled trial that "[o]ffering financial incentives to patients with psychotic disorders who have poor adherence to maintenance treatment with antipsychotics is effective in improving adherence." 16 The same study team has more recently concluded that these incentives can be made cost-effective. ${ }^{17}$

Financial incentives have also been used in practice to incentivize treatment ${ }^{18}$ and attendance at day treatment for mentally ill individuals also involved in substance abuse. ${ }^{19}$ However, a recent report concludes that "[e]ven though financial incentives seem to be an effective strategy for enhancing medication adherence, there is no appetite among clinicians to use them in practice." 20 The article observes that none of the teams participating in the Priebe et al. study continued the intervention after the study's end, despite the fact that it showed effective results. ${ }^{21} \mathrm{~A}$ related qualitative study suggests that providers viewed payments for adherence to mental health medications as inherently wrong, ${ }^{22}$ and an earlier article reports that more than three-quarters of providers had objections to such payments. ${ }^{23}$

16 Stefan Priebe et al., Effectiveness of Financial Incentives to Improve Adherence to Maintenance Treatment with Antipsychotics: Cluster Randomised Controlled Trial, 347 BMJ e0138816 (2013).

17 Catherine Henderson et al., Cost-Effectiveness of Financial Incentives to Promote Adherence to Depot Antipsychotic Medication: Economic Evaluation of a Cluster-Randomised Controlled Trial, 10 PLOS ONE e0138816 (2015).

18 Stephen Pereira, Dominic Beer \& Carol Paton, Enforcing Treatment with Clozapine: Survey of Views and Practice, 23 PsychIATRIC BULL. 342, 345 (1999).

19 Kate B. Carey \& Michael P. Carey, Enhancing the Treatment Attendance of Mentally Ill Chemical Abusers, $21 \mathrm{~J}$. BEHAV. THERAPY \& EXPERIMENTAL PSYCHIATRY 205, 208 (1990).

20 Rebecca Gray, Cash, Choice, Antipsychotic Medication and the Mental Health Nurse, 22 J. Psychiatric \& Mental Health Nursing 149, 152 (2015).

$21 \quad I d$.

22 Elizabeth Brown \& Rebecca Gray, Tackling Medication Non-Adherence in Severe Mental Illness: Where Are We Going Wrong?, 22 J. PsyCHIATRIC \& MENTAL HEALTH NuRSING 192, 196 (2015).

23 Dirk Claassen et al., Money for Medication: Financial Incentives to Improve Medication Adherence in Assertive Outreach, 31 PsYCHIATRIC BULL. 4, 5 


\section{Substance Use Cessation}

Some substances, such as cocaine and nicotine, are both harmful to health and psychologically and physically addictive. Addiction weakens the patient's capacity to stop using the substance, potentially preventing patients who want to reduce or stop their substance use from doing so. Financial incentives have been proposed as a way of buttressing patients' psychological capacity to stop substance use.

Emma Giles and co-authors conducted a systematic review and meta-analysis in 2014 examining payments to patients to encourage smoking cessation. ${ }^{24}$ They identified and reviewed ten studies on the topic and ultimately concluded that payments are an effective way of motivating the decision to stop smoking. In an earlier review, Giuffrida and Torgerson mention several studies that provided incentives for substance use cessation. ${ }^{25}$ The studies they identify include the following interventions:

- Vouchers worth $\$ 3$ given to mentally ill substance abusers who attended treatment sessions; 26

- Payments to patients in exchange for their compliance with a naltrexone treatment regimen; ${ }^{27}$

- The provision of vouchers worth varying amounts to patients who abstained from cocaine use, with a patient who remained abstinent for twelve weeks receiving approximately $\$ 1000 ;{ }^{28}$

- Payment to patients in a methadone treatment program who provided drug-free urine samples. ${ }^{29}$

Many of these studies concluded that paying patients was

(2007).

24 Emma L. Giles et al., The Effectiveness of Financial Incentives for Health Behaviour Change: Systematic Review and Meta-Analysis, 9 PLOS ONE e90347 (2014).

25 Giuffrida \& Torgerson, supra note 15 , at 704.

26 Carey \& Carey, supra note 19, at 206-207.

27 J. Grabowski et al., Effects of Contingent Payment on Compliance with a Naltrexone Regimen, 6 AM. J. DRUG \& AlCoHoL ABUsE 355, 355 (1979).

28 Stephen T. Higgins et al., A Behavioral Approach to Achieving Initial Cocaine Abstinence, 148 AM. J. Psychiatry 1218, $1219-20$ (1991) Thereinafter Higgins et al., A Behavioral Approach]; Stephen T. Higgins et al., Incentives Improve Outcome in Outpatient Behavioural Treatment of Cocaine Dependence. 51 Archives Gen. Psychiatry 568, 574-75 (1994); John R. Hughes, Florian Foerg \& Gary Badger, Achieving Cocaine Abstinence with a Behavioral Approach, 150 Am. J. PsychIATRY 763, 769 (1993).

29 Mary E. McCaul et al., Contingency Management Interventions: Effects on Treatment Outcome During Methadone Detoxification, 17 J. APPLIED BEHAV. ANALYSIS 35, 35-36 (1984). 
effective at improving adherence. ${ }^{30}$ Recent work on vaccinations against cocaine and methamphetamine addiction similarly mentions the possibility of using a payment model. ${ }^{31}$

\section{Communicable Disease Treatment}

Because patients infected with communicable diseases pose risks of infection to others, treating them benefits society in general as well as the infected individuals themselves. However, treatments for some infections can either require a long course of medication that can make adherence difficult or require testing in patients who are asymptomatic and may not perceive a need for testing. Financial incentives have been used in several studies to encourage patients to adhere to treatment protocols for infectious disease:

- Patients were paid to return and obtain their tuberculosis skin test reading, where an incentive of $\$ 10$ dramatically increased rates of return; ${ }^{32}$

- Patients were paid to adhere to a vaccination schedule for Hepatitis $B$ that required seven administrations, where a $\$ 10$ incentive for each session attended substantially increased adherence; 33

- Patients were paid to receive influenza vaccinations, increasing the rate of vaccination; ${ }^{34}$

- Patients were paid to attend tuberculosis follow-up appointments, increasing adherence, ${ }^{35}$

- Injectable drug users were paid to attend education about HIV prevention, which was found to be effective, and more effective than nonmonetary incentives; ${ }^{36}$ and

- Public health scholar and activist Paul Farmer used

30

31 Brit. J. Clinical Pharmacology 368, 372 (2013) (discussing "outpatient contingency management, in which patients are paid to come for the vaccinations with an escalating pay schedule for each vaccination obtained").

32 C. Kevin Malotte, Fen Rhodes \& Kathleen E. Mais, Tuberculosis Screening and Compliance with Return for Skin Test Reading Among Active Drug Users, 88 AM. J. Pub. Health 792, 792 (1998).

33 Maxine L. Stitzer et al., Drug Users' Adherence to a 6-Month Vaccination Protocol: Effects of Motivational Incentives, 107 DRUG \& ALCOHOL DEPENDENCE 76 (2010).

34 Mary Patricia Nowalk et al., Improving Influenza Vaccination Rates in the Workplace: A Randomized Trial, 38 Am. J. Preventive Med. 237, 244 (2010).

35 Louise Pilote et al., Tuberculosis Prophylaxis in the Homeless: A Trial to Improve Adherence to Referral, 156 ARCHIVES INTERNAL MED. 161, 165 (1996).

36 Sherry Deren et al., The Impact of Providing Incentives for Attendance at AIDS Prevention Sessions, 109 Pub. Health REP. 548, 552 (1994). 
financial incentives to encourage treatment followthrough among tuberculosis patients. ${ }^{37}$

These interventions allow society to incentivize patients to become non-infectious and to lower their odds of infecting others, benefitting both the patients and society in general.

\section{Other Examples}

In some cases, payment for adherence can serve a similar function to payment for cost-effectiveness. Phototherapy (ultraviolet light treatment) for psoriasis represents one example. Even though phototherapy is safe, effective, and more cost-effective than alternative treatments, patients tend not to complete courses of phototherapy because these courses require numerous sessions, each of which is inconvenient and requires co-payment costs. A recent study suggests that a "reverse' copayment (paying patients for sessions attended) of $\$ 10$ per visit for phototherapy and increased physician reimbursement of $\$ 10$ per treatment could encourage phototherapy utilization and save thousands of dollars per patient in avoiding highercost pharmacologic interventions." 38 Just like the shared savings proposal suggested by Schmidt and Emanuel, ${ }^{39}$ paying patients to receive phototherapy can enable insurers to achieve net per-patient savings; to the extent that phototherapy is also more absolutely effective than the alternatives, it can enable patients to overcome their inconvenience-related aversion to it.

\section{Paying for Cost-Effectiveness or Lower Cost}

The economics of health care differ from the economics of many other important goods, such as housing or food, in that the individuals paying for the intervention frequently are not the individuals who benefit. Many of the actors who bear some of the cost of paying for health care interventions, such as health insurers, employers, and governments, therefore have a motivation to pay patients to select more cost-effective treatments-or even treatments that are simply cheaper. Allowing patients to receive a payment in exchange for waiving their entitlement to costly medical interventions could leave both patients and payers better off, since patients may value the payment more than the intervention, while payers may find it more affordable to pay patients to waive entitlements

Paul Farmer et al., Tuberculosis, Poverty, and "Compliance": Lessons from Rural Haiti, 6 Seminars ResPiratory Infections 254, 256 (1991).

38 Gregory L. Simpson et al., Do Utilization Management Controls for Phototherapy Increase the Prescription of Biologics?, $17 \mathrm{~J}$. DERMATOLOGICAL TREATMENT 359, 360 (2006).

39 See infro notes 40-44 and accompanying text. 
than to provide interventions. These payments often do not constitute Pareto-efficient improvements, in which some people are made better off and none are made worse off, because they deprive producers and providers-such as physicians and drug manufacturers - of profit opportunities. However, producers and providers lack any obvious right to have patients purchase what they sell at the current going price. Instead, payments will put pressure on producers and providers to lower prices or provide better-quality interventions.

Two recent proposals have made the case for paying patients to decline expensive treatments in favor of selecting alternatives that are more cost-effective or in favor of declining treatment altogether. The first approach focuses on costeffectiveness, while the second focuses on cost alone.

Harald Schmidt and Ezekiel Emanuel develop the first proposal, "inclusive shared savings," in a recent article in JAMA Internal Medicine. ${ }^{40}$ Inclusive shared savings resembles value-based insurance, which lowers or eliminates insurance out-of-pocket costs for patients who elect to use more costeffective interventions. However, it goes beyond value-based insurance's elimination of out-of-pocket costs to affirmatively pay patients in exchange for their selecting cost-effective treatments. They describe inclusive shared savings using the example of chemotherapies for gastric cancer:

$[\mathrm{U}]$ nder inclusive shared savings the oncologist would tell the patient about the therapeutically equivalent chemotherapies for advanced gastric cancer. If the patient selected the least expensive treatment, the co-payments would be eliminated and the patient would also receive a payment. If the patient chose a more costly treatment, the payment would decrease. There would be no financial incentive to choose the most expensive option. A specific formula for determining the patient's payment would have to be developed. For example, the payment might be a percentage based on the actual reduction in total cost of care. The amounts of the payments should be sufficiently large that they would be meaningful to patients while still contributing to substantial overall cost reductions. ${ }^{41}$

Schmidt and Emanuel identify existing precedents for inclusive

Harald Schmidt \& Ezekiel J. Emanuel, Lowering Medical Costs Through the Sharing of Savings by Physicians and Patients: Inclusive Shared Savings, 174 JAMA INTERNAL MED. 2009, 2009 (2014).

$41 \quad$ Id. at 2012. 
shared savings, including practices outside of medicine ("some hotels provide guests with a $\$ 5$ voucher for every day that they forego housekeeping services" ${ }^{42}$ ), as well as a current example from the Medicare system:

In health care, Medicare's acute care episode demonstration project provides a bundled payment to physicians and hospitals for 37 orthopedic and cardiac procedures, such as hip replacements. Patients' co-payments are waived, and patients are offered a $\$ 275$ incentive for receiving their treatment through the demonstration. ${ }^{43}$

Schmidt and Emanuel then argue for inclusive shared savings on the basis that it more fairly distributes the savings from reducing the cost of care, incentivizes patients more powerfully than the mere elimination of copayments, and encourages shared decision making. (In earlier work, Richard Saver similarly proposes that the expansion of "gainsharing" programs, in which insurers and providers share the benefits of more cost-effective health care delivery, should include patients in gainsharing as well. ${ }^{44}$ ) Inclusive shared savings could be adopted directly by private insurers or employers, but could also be proposed by governments or non-governmental organizations. As Emanuel and Schmidt indicate, the amount of the payment could be calibrated to the change in the cost of care, to the improvement in cost-effectiveness, or to some other metric.

Christopher Robertson has made a similar but simpler proposal, which focuses only on cost rather than costeffectiveness. Robertson proposes the "split benefit," a model under which insurers pay patients some fraction of the price of a costly intervention they are entitled to receive, and the patient then gets to decide whether to choose the costly intervention-turning over that fraction as a copayment-or instead to retain the fraction and go without the intervention. ${ }^{45}$ Robertson and co-authors have examined the potential efficacy of the split benefit in an empirical study and have argued that many patients would select the money rather than the intervention. ${ }^{46}$ Prior to Robertson's work, two economists

Id.

Id.

Richard S. Saver, Squandering the Gain: Garnishing and the Continuing Dilemma of Physician Financial Incentives, 98 Nw. U. L. REV. 145, 228-31 (2003).

45 Christopher Robertson, The Split Benefit: The Painless Way to Put Skin Back in the Health Care Game, 98 CORNELl L. Rev. 921, 944-46 (2013).

46 Christopher T. Robertson et al., A Randomized Experiment of the Split 
similarly suggested that patients be able to waive their right to certain expensive end-of-life treatments in exchange for payments. ${ }^{47}$

The split-benefit structure allows patients to decline expensive care when they would prefer to have the money instead-like inclusive shared savings, it pays patients to decline treatments that are expensive, but to which they would otherwise be entitled. However, unlike inclusive shared savings, it does not focus specifically on cost-effectiveness, because the payment to the patient reflects the absolute cost of the intervention rather than the cost-effectiveness of the cheaper alternative. In some circumstances, the split benefit could lead to patients selecting a cheaper but less cost-effective treatment, or turning down treatments that are cost-saving for society overall, in order to receive more money.

\section{Paying for Health Decisions and Outcomes}

\section{Paying for Health Improvement}

Many organizations who pay for patient care costs, such as employers, insurers, and even governments, have instituted workplace wellness programs that use what some have called "Pay for Performance for Patients." 48 These programs include monetary incentives for certain behaviors, such as weight loss, smoking cessation, or participation in various wellness programs, or to reach certain biomedical targets such as body mass index or blood pressure levels. Some of these incentive programs, such as those for smoking cessation, overlap with the adherence programs discussed in the prior Section, but many extend to cover not only adherence but also the achievement of health outcomes.

These programs have produced substantial discussion, and the Affordable Care Act codified permission for employers to

Benefit Health Insurance Reform to Reduce High-Cost, Low-Value Consumption, 1 InNOvation \& EnTREPREnEURShip Health 5, 5-6 (2014).

47 Margaret M. Byrne \& Peter Thompson, Death and Dignity: Terminal Illness and the Market for Non-Treatment, 76 J. PUB. ECON. 263, 277 (2000); cf. Corey J. Ayling, New Developments in ERISA Preemption and Judicial Oversight of Managed Care, 31 CREIGHTON L. REv. 403, 405 n.14 (1998) ("Perhaps . . . the patient should be given year-end bonuses for limiting her health care or for avoiding disfavored and expensive treatments like cardiology care . . . . It may well be far more efficient to turn doctors into salaried advisors and to pay patients significant bonuses for using health services sparingly. This system has yet to evolve, perhaps because of the fear of encouraging foolish, short-term decision making by patients or perhaps because of the fundamental principle of insurance that the well subsidize the sick.")

48 Judith A. Long, Marie Helweg-Larsen \& Kevin G. Volpp, Patient Opinions Regarding 'Pay for Performance for Patients,' 23 J. Gen. InTERnal Med. 1647 (2008). 
engage in them. ${ }^{49}$ One distinction drawn in the literature contrasts interventions that pay for effort toward health improvement with those that pay for the achievement of health outcomes, although the ethical relevance of this distinction is debatable. ${ }^{50}$

\section{Paying for Other Health Choices}

In some cases, individuals are paid to make health-related choices that do not straightforwardly improve their own health, but instead advance the interests (both health-related and otherwise) of society or of specific third parties.

Individuals are frequently paid to take health risks. Certain jobs-ranging from football to nuclear waste disposal to infectious disease nursing-involve employees being paid to engage in activities that put their health at risk. Two contexts where individuals are paid as part of an agreement that involves taking on health risks have received particular attention: (1) clinical research on human subjects ${ }^{51}$ and (2) organ and tissue donation. ${ }^{52}$

Another common context featuring proposals to pay patients involves the exercise of reproductive capacities. One financial incentive that has engendered substantial discussion is the "dollar a day" proposal advanced by Sunstein and Thaler. This is a program in which teenagers are paid one dollar per day to avoid becoming pregnant. ${ }^{53}$ (It is unclear whether the

See generally Kristin M. Madison, Kevin G. Volpp \& Scott D. Halpern, The Law, Policy, and Ethics of Employers' Use of Financial Incentives to Improve Health, 39 J. L. MED. \& ETHICS 450 (2011) (providing a comprehensive review of financial incentive use in the employment context that touches on legal, ethical, and economic dimensions of incentives).

50 Harald Schmidt, David A. Asch \& Scott D. Halpern, Fairness and Wellness Incentives: What is the Relevance of the Process-Outcome Distinction?, 55 PREVENTIVE MED. S118 (2012).

51 For perspectives friendly to payment, see generally Christine Grady, Payment of Clinical Research Subjects, 115 J. CLINICAL INVESTIGATION 1681 (2005); Scott D. Halpern, Financial Incentives for Research Participation: Empirical Questions, Available Answers and the Burden of Further Proof, 342 AM. J. MED. SCI. 290 (2011); and Alan Wertheimer \& Franklin G. Miller, Payment for Research Participation: A Coercive Offer?, 34 J. MED. ETHICs 389 (2008). For more skeptical perspectives, see generally Carl Elliott \& Roberto Abadie, Exploiting a Research Underclass in Phase 1 Clinical Trials, 358 New Engl. J. MED. 2316 (2008); Ruth Macklin, The Paradoxical Case of Payment as Benefit to Research Subjects, 11 IRB: EthICS \& Hum. RES. 1 (1989); and Janice C. Wong \& Mark Bernstein, Payment of Research Subjects for More than Minimal Risk Trials Is Unethical, 342 AM. J. MED. SCI. 294 (2011).

52 Compare Francis L. Delmonico et al., Ethical Incentives-Not Payment-for Organ Donation, 346 NEw ENGL. J. MED 2002 (2002), with JANET RADCLIFFE Richards, The Ethics of Transplants: Why CaReless Thought Costs Lives (2012).

53 Richard H. Thaler \& Cass R. Sunstein, Nudge: Improving Decisions about 
program worked. ${ }^{54}$ ) Other organizations have offered to pay women who agree to long-term sterilization. ${ }^{55} \mathrm{On}$ the other side, some have proposed paying women not to choose abortions. ${ }^{56}$

An interesting hypothetical would involve the parents of children with disabilities paying prospective parents who choose to have children with similar disabilities. Individuals with a given disability may derive benefits from there being a larger community of individuals with the same disability. ${ }^{57}$ Though these discussions do not typically use this terminology, the benefits are positive "network externalities" for the existing families, just as the preservation of a spoken language or a media format is a positive network externality for those who speak that language or use that media format. The existence of this positive externality makes it economically sensible to pay individuals to provide it, though not necessarily ethically sensible for there to be a regime of such payments.

\section{Paying Patients: Ethical Issues}

Many of the legal issues raised by payments to patients, which I will discuss in Part IV, are intertwined with normative issues. Understanding what sorts of contracts are against public policy, or what types of discrimination are objectionable, requires examining normative concepts. Furthermore, normative issues are of interest both as we consider what the legal landscape should be like-as opposed to what it is likeand as we consider non-legal questions such as what professional obligations providers might owe to patients.

HeALTh, WEALTH, AND HAPPINESS 234 (2008).

54 Gerd Gigerenzer, On the Supposed Evidence for Libertarian Paternalism, 6 Rev. Phil. \& Psych. 361, 363 n.1 (2015); Catherine Stevens-Simon et al., The Effect of Monetary Incentives and Peer Support Groups on Repeat Adolescent Pregnancies: A Randomized Trial of the Dollar-a-Day Program, 277 JAMA 977, 981 (1997).

55 See Govind Persad, Libertarian Patriarchalism: Nudges, Procedural Roadblocks, and Reproductive Choice, 35 WOMEN's RTS. L. REP. 273, 283 (2013).

56 Stephen G. Gilles, Should Pregnancy Help Centers Offer Post-Natal Financial Support to Reduce the Incidence of Abortion?, 13 AVE MARIA L. REv. 21, 23 (2015); Jennifer Graham, Meet the Retired Nurse Who Pays Women Not To Have Abortions, DESERET NEws (June 24, 2016), http:/www.deseretnews.com/article/865656672/Meet-the-retired-nurse-whopays-women-not-to-have-abortions.html [http:/perma.cc/M78U-LUSA].

57 E.g., Amy Harmon, Prenatal Test Puts Down Syndrome in Hard Focus, N.Y. TIMEs (May 9, 2007), http://www.nytimes.com/2007/05/09/us/09down.html [http://perma.cc/8WN5-AMJP] ("If all these people terminate babies with Down syndrome, there won't be programs, there won't be acceptance or tolerance,' said Tracy Brown, 37, of Seattle, whose 2-year-old son, Maxford, has the condition. 'I want opportunities for my son. I don't know if that's right or wrong, but I do."”). 
There are few comprehensive reviews of the ethical issues associated with payments to patients. Some authors have examined the ethical issues raised by market transactions or market incentives in general, ${ }^{58}$ and others have looked at the ethical issues raised by specific types of payments, such as wellness programs offered by insurers. ${ }^{59}$ This Section provides a more coherent and comprehensive review of ethical concerns that creates a taxonomy for the ethical concerns that payments to patients raise; provides an evaluation of how compelling those concerns should be; and identifies directions for future empirical and conceptual research.

\section{A. Concerns About Deliberative Autonomy}

One family of ethical concerns about payments to patients focuses on ways in which payments might interfere with patients' capacity to deliberate effectively about their medical options and interests. Examples of such interference include coercion, undue inducement, and what I call "deliberative diversion." I argue that payments do not coerce, and that whether they constitute undue inducements is largely an empirical question. The most compelling arguments involve deliberative diversion, but deliberative diversion may not be sufficiently objectionable to justify a prohibition on payments.

\section{Coercion}

Promberger et al. report that "even if effective, offering financial incentives to motivate health-enhancing behavior attracts opprobrium in lay and professional media." ${ }^{60}$ This opprobrium stems in part, they contend, from the belief that such incentives are coercive.

Whether payments are coercive depends on what account of coercion we adopt. One plausible account is that an individual is coerced to do $X$ if and only if she is threatened with being made worse off than she has a right to be unless she does $X{ }^{61}$ Alan Wertheimer and Franklin Miller argue that payments to patients in research are not coercive under this definition

See, e.g., Elizabeth Anderson, Value in Ethics and Economics (1995); Jason F. Brennan \& Peter Jaworski, Markets Without Limits: Moral Virtues and COMmercial Interests (2015); Ruth W. Grant, Strings Attached: Untangling the Ethics of InCentives (2011); Debra Satz, Why Some Things Should not Be for Sale: The Moral Limits of Markets (2010).

59 E.g., Harald Schmidt, Bonuses as Incentives and Rewards for Health Responsibility: A Good Thing?, 33 J. MeD. \& PHIL. 198, 208-09 (2008).

60 Marianne Promberger et al., Acceptability of Financial Incentives to Improve Health Outcomes in UK and US Samples, 37 J. Med. ETHICs 682, 682 (2011).

61 Wertheimer \& Miller, supra note 51, at 390. 
because they do not threaten to make patients worse off than they have a right to be: they are offers, not threats. ${ }^{62}$ While there may be other reasons for concern about such payments, they do not coerce. Though they focus on clinical research, Wertheimer and Miller's argument extends to payments to patients more broadly: patients are not deprived of anything to which they have a right when they are offered payment, and therefore are not coerced. So, for instance, participants in an inclusive shared-savings program or in a smoking-cessation program are not coerced when they are offered money if they choose cost-effective interventions or take steps to cease smoking.

The most promising objection to the claim that payments never coerce argues that payments can be coercive when (1) the recipient of the offer is facing very bad circumstances and (2) the offer is very attractive in light of those circumstances, although the recipient's situation after accepting the offer will still be a bad one. An example is Joel Feinberg's "lecherous millionaire" example, in which a millionaire offers a woman with a dying child treatment for her child in exchange for her becoming the millionaire's mistress. ${ }^{63}$ The objection, however, fails because it conflates exploitation with coercion. While the lecherous millionaire's offer may be objectionable, it is not coercive, because the offer itself does not make the offeree worse off than she has a right to be. Rather, the offer proposes to take advantage of the offeree's vulnerability, and therefore may be exploitative (and therefore morally wrong all the same). ${ }^{64}$

Offers of payment may be coercive if we accept some other account of coercion. However, Wertheimer's account-or some similar account that defines coercion in terms of wrongful threats-is the most plausible one available. Defining coercion in terms of interests rather than rights (as in threatening to make someone worse off than they prefer to be) classifies far too many cases as coercive, while defining coercion counterfactually (as in threatening to make someone worse off than they would otherwise be) classifies too few cases as coercive. ${ }^{65}$ Wertheimer and Miller, 36 J. MeD. ETHICS 383, 384 (2010) (citing JOEL FEINBERG, HARM To SELF (1986)).

64 On exploitation, see infra Section II.B.1.

65 Scott Anderson, Coercion, in The Stanford Encyclopedia of Philosophy $\begin{array}{lllll}\text { (Edward N. Zalta } & \text { ed. }\end{array}$ http://plato.stanford.edu/archives/sum2015/entries/coercion/ [http://perma.cc/GZ6F-9VAX]. 


\section{Undue Inducement}

Some offers of payment to patients may be undue inducements in that they impair patients' capacity to deliberate rationally about what medical decisions to make. The definition of undue inducement, however, is debated. One definition of undue inducement, adopted by the Council for International Organizations of Medical Sciences (CIOMS) in its Guideline 7 for clinical research and defended by Ezekiel Emanuel, sees undue inducements as payments that produce deliberative misjudgments:

Payment in money or in kind to research subjects should not be so large as to persuade them to take undue risks or volunteer against their better judgment. Payments or rewards that undermine a person's capacity to exercise free choice invalidate consent. ${ }^{66}$

Emanuel et al. suggest that undue inducements must meet four criteria:

1) an offered good-individuals are offered something that is valuable or desirable in order to do something;

2) excessive offer-the offered good must be so large or in excess that it is irresistible in the context;

3) poor judgment - the offer leads individuals to exercise poor judgment in an important decision;

4) risk of serious harm-the individuals' poor judgment leads to sufficiently high chance that they will experience a harm that seriously contravenes his or her interests. ${ }^{67}$

Other authors have offered similar criteria that emphasize that an inducement must have a psychologically distorting effect in order to be undue, such that the individual, if deliberating coolly and in light of her considered commitments, would not

Ezekiel J. Emanuel, Xolani E. Currie \& Allen Herman, Undue Inducement in Clinical Research in Developing Countries: Is It a Worry?, 366 LANCET 336, 337 (2005).

67 Id. Angela Ballantyne similarly observes that "[i]nducement payments for research subjects are thought to be 'undue' when they distort the judgement of potential research subjects and undermine the voluntariness of the subject's consent." Angela Ballantyne, Benefits to Research Subjects in International Trials: Do They Reduce Exploitation or Increase Undue Inducement?, 8 DEVELOPING WORLD BIOETHICS 178, 184 (2008). 
accept the inducement. ${ }^{68} \mathrm{~A}$ study by Largent et al. indicates that institutional review board members reviewing clinical research protocols agree that "an offer constitutes undue influence if it 'distorts a subject's ability to perceive accurately the risks and benefits of research." 69

The question that this definition raises is when, if ever, offers of money genuinely do distort patients' ability to perceive risks and benefits. Empirical studies in the research-ethics context suggest that prospective subjects do not believe that offers of money genuinely distort risk/benefit perception; if subjects are correct, few payments would constitute undue inducements in CIOMS's sense. ${ }^{70}$ This perception finds some support from work that concludes that greater payments make subjects, if anything, more vigilant about the possibility of harm. ${ }^{71}$ It would be valuable to conduct similar studies for payments to patients outside the research-ethics context, such as inclusive-shared-savings payments or payments for adherence.

A different definition of undue inducement regards an inducement as undue when it is highly deliberatively significant, even when the patient's deliberation is undistorted. There are at least two potential standards for deliberative significance. One is the view that a financial inducement is undue whenever it leads a patient to do something she otherwise would not have done. One empirical survey found that eighty percent of respondents believed that, in the research context, an "offer of payment constitutes undue influence simply because it motivates someone to do something they otherwise would not." ${ }^{2}$ This view, however, generates an overbroad definition of undue inducement on which any successful payment incentive would be unduly influential, because it succeeds in getting people to do something they would not do sans incentive. Many payments in daily life would also be unduly influential-for instance, I unduly influence someone to mow my lawn if she would not have done so unpaid.

See Wertheimer \& Miller, supra note 51, at 391 ("[A]n inducement is undue only when it predictably triggers irrational decision-making given the agent's own settled (and reasonable) values and aims."); cf. Colleen C. Denny and Christine Grady, Clinical Research with Economically Disadvantaged Populations, 33 J. MED. ETHICs 382, 383 (2007) ("To avoid confusion, we use the phrase 'decision-impairing inducement' to emphasise how the offer of certain goods is thought to impair an individual's ability to make rational choices.").

69 Emily A. Largent et al., Money, Coercion, and Undue Inducement: A Survey of Attitudes About Payments to Research Participants, 34 IRB 1, 6 (2012).

70 David Casarett, Jason Karlawish \& David A. Asch, Paying Hypertension Research Subjects, 17 J. Gen. InTERnAL MED. 651, 653 (2002).

71 Cynthia E. Cryder et al., Informative Inducement: Study Payment as a Signal of Risk, 70 SOC. SCI. MED. 455, 460 (2010).

72 Largent et al, supra note 69 , at 6. 
The other potential standard for deliberative significance is the view that a financial inducement is undue whenever it leads a patient to do something she would otherwise have strongly rejected (i.e., whenever the inducement is so large that its value overwhelms any concerns the patient might have). This is somewhat more plausible, though in the end it is more properly classified as a concern about deliberative diversion, discussed next. But very few financial inducements are large enough to produce this scenario.

Many examples leave it unclear how undue inducement is being defined. Tom Beauchamp and Ruth Faden, for instance, offer the following example:

Researchers offer Mary $\$ 25$ per day in exchange for her participation in research involving repeated, "painful and invasive medical procedures." Mary is terrified of participating in the research, but badly needs money. "Mary wishes desperately that she had never received such an offer because once it is made, she feels she must accept, whereas beforehand she would never have been faced with such a tragic "choice." 73

It is unclear why Mary prefers not to have received the offer. One possibility is that the offer distorts her deliberative capacities such that she feels psychologically compelled to agree even though her considered judgment would reject the offer-the offer is analogous to offering a drink to an alcoholic. But if Mary's considered judgment is that she would prefer to receive $\$ 25$, even for the terrifying research, than not to participate, then it is not clear why the inducement is undue. It may be exploitative or otherwise unjust, but the problem does not lie in its effects on Mary's deliberation.

\section{Deliberative Diversion and Deliberative Insulation}

Discussions of both coercion and undue inducement, particularly by authors who attempt to justify expansive understandings of those concepts, suggest that the concern at issue is not truly about deliberative distortion or about individuals being left without choices. Rather, the concernone that has not so far been well defined in the literatureinvolves the value to patients of being able to deliberate in a way that is insulated from financial considerations, which

73 Matt Lamkin, Health Care Reform, Wellness Programs and the Erosion of Informed Consent, 101 KY. L.J. 435, 447 (quoting RUTH R. FADEN \& TOM L. BEAUCHAMP, A HisTORY AND THEORY OF INFORMED CONSENT $358-59$ (1986)) 
paying patients to make decisions undermines. This is a conceptual rather than empirical point: the claim is not that patients' deliberation is actually made worse, but instead that the meaning of the deliberation is changed by the presence of financial considerations.

The legal scholar Seana Shiffrin offers a detailed explanation of what I call "deliberative insulation" in her discussion of the value of subsidizing certain individual choices, including choices to make certain health-jeopardizing decisions such as smoking:

Accommodation restricts the sorts of reasons the agent and those who interact with her must consider. To varying degrees, creating insulated areas allows an agent to focus on some of the distinctive reasons associated with the activity. It protects her from worrying about certain goods and reasons only contingently or indirectly associated with the activity. Our medical premium and privacy practices permit a person to evaluate whether to smoke by considering the reasons closely associated with the activity: the social and sensory pleasures (and costs) and the health risks, without having the deliberation salted by other sorts of reasons presented by the threats of job loss, severe income fluctuation, deprivation of health care, and social ostracism. Such other reasons may tend to dominate and overshadow those reasons associated with the activity itself. ${ }^{74}$

Shiffrin goes on to further explain the value of being able to focus narrowly on a more limited set of considerations:

This sort of focus is valuable partly because it helps to facilitate the agent's integrity-some sorts of decisions are highly delicate and agents are prone to distraction and temptation. But more than that, it promotes a certain sort of freedom. It allows an agent to respond to a certain range of reasons that might otherwise be dominated by considerations relating to others, by morality, or by physical and financial need; in so doing, it permits her the chance to exercise a particular aspect of her capacity for choice. This permits her to exercise a certain range of 
capacities for choice without having to exercise others. The smoker may, in some (quite limited) sphere, exercise her capacities for making choices about her body and her physical experiences, without also having to engage her capacities for moral deliberation or prudential financial planning. Even a very limited and constricted opportunity to respond to certain sorts of important reasons and to exercise certain capacities for choice in ways that are not fully dominated by other considerations seems like a part of autonomy's value that is worth protecting. ${ }^{75}$

Shiffrin's discussion is focused on the subsidization of behavior (the elimination of financial penalties), but it also seems applicable to the limitation or elimination of financial incentives. By enrolling in a smoking cessation study that pays her for each day she avoids smoking, a smoker may improve her odds of quitting, but she allows considerations about financial planning to seep into her judgment about whether to smoke-her deliberation is, as Shiffrin puts it, "salted" by those considerations and diverted from a narrower focus.

For those who find Shiffrin's smoker example too stylized, consider a different case. Imagine that as you were considering whether to propose to your spouse, your in-laws had offered you a sizable sum of money to do so in view of their desire for grandchildren. Even though you might normally be happy to receive a financial incentive to do something you would have liked to do anyway-imagine finding out that your favorite brand of cereal comes with a cash-back rebate-the intrusion of these financial considerations into your decision about whether to propose could be unwelcome. It would make it more difficult to conclude reflectively that you decided to propose out of love, rather than for some other reason.

Somewhat further afield, Kimberly Yuracko argues that working in "sex-plus" jobs, which involve both the sale of sexual arousal and of some other good, can produce deliberative and role confusion: "A clearly problematic job ... . is one that requires a woman to work as a chemistry professor from nine to five and then perform a striptease for the administrative staff at five every afternoon." 76 She concludes that there is value to protecting "women's ability to develop as intellectual and rational actors by carving out a space for them in the work world where they cannot be formally and explicitly

Id. at 247-48.

76 Kimberly A. Yuracko, Private Nurses and Playboy Bunnies: Explaining Permissible Sex Discrimination, 92 CAL. L. REV. 147, 203-04 (2004). 
sexualized." 77 Having to consider both financial and health considerations may create similar forms of role confusion, and there may be distinctive value in being able to focus on only one.

Some criticisms of payments to patients, even if presented in the language of undue inducement or coercion, are most charitably understood as referencing an ideal of deliberative insulation along the lines defended by Shiffrin and Yuracko. These criticisms generally make the case that patients should make decisions about research participation by focusing on the effects participation will have on their own health and on the public good, but-importantly-not on how participation will affect financial well-being. Alex John London develops what I take to be a paradigm case of a deliberative-insulation account. London observes that "the reasons that individuals choose to participate as participants in scientific research matter" and that we want individual participation to be motivated by medical or altruistic reasons rather than financial ones:

[W]e want to ensure that participants are not induced to participate in research in which they would not participate if they were to evaluate it solely in terms of its potential for direct personal benefit (as opposed to indirect benefits deriving from incentives to participate) or in terms of its merits as a means by which they might contribute to the fund of human knowledge. ${ }^{78}$

London concludes that the permissibility of research participation should hinge on "whether the trial participants themselves view the research as a worthwhile means of advancing their own interest in benefiting directly from the research activity or as advancing their own interest in contributing to the common good through research participation. ${ }^{79}$ Even though London describes his view as a definition of undue inducement, I would classify it as one that insists on the importance of deliberative insulation. Jeanne Sears similarly endorses the view that "[i]deally, a decision about whether or not to volunteer for research should reflect the values of the individual concerned and nothing else." ${ }^{80} \mathrm{In}$

77 Id. at 202

78 Alex John London, Undue Inducements and Reasonable Risks: Will the Dismal Science Lead to Dismal Research Ethics?, 5 AM. J. BIOETHICs 29, 31 32 (2005).

$79 \quad$ Id. at 32

80 Jeanne M. Sears, Payment of Research Subjects: A Broader Perspective, 1 AM J. Bioethics 66, 67 (2001); cf. Christine Grady, Money for Research Participation: Does It Jeopardize Informed Consent?, 1 Aм. J. BIовтнICS 40, 42 (2001) ("It is sometimes argued that since research participants volunteer 
the egg-donation context, one commentator discusses similar concerns that "[p]ayment threatens to compromise the 'good' motivation of desiring to help with the taint of the 'bad' motivation of desiring to make money." ${ }^{81}$ Other criticisms of payment incentives in the research context similarly reference the importance of patients selecting trial participation "for the right reasons." 82

Deliberative diversion identifies a genuinely important reason to be concerned about paying patients. Whether it justifies a prohibition on payments, however, is less clear. First, financial motivations can coexist with non-financial ones, so even if financial motivations do intrude on deliberations, they need not swamp all other motivations. Second, deliberative insulation, even if desirable, may not be sufficiently important to justify prohibiting payment. Laura Siminoff argues that

[t]he ethical duty of the research community is not to be "thought police" guarding against subjects' making decisions for "wrong" reasons, but to assure that the research we are asking subjects to consider participating in is not so onerous or so dangerous that participation would seriously threaten their health and safety. ${ }^{83}$

Siminoff's argument is somewhat uncharitable, since the goal

with altruistic motives of contributing to science and society, money has no place in this arrangement. The ethical concern, then, is not simply that some might find the offer of money irresistible, but also that money is simply an inappropriate motivating factor for research participation.").

81 Charis Thompson, Why We Should, in Fact, Pay for Egg Donation, 2 REGENERATIVE MED. 203, 205 (2007).

82 Benjamin Hale, Risk, Judgment and Fairness in Research Incentives, 7 AM. J. Bioethics 82, 83 (2007); see also Lainie Friedman Ross, Payment in Pediatric Research, 9 J. MED. \& L. 1, 1 (2005) ("Ideally, research subjects would be motivated by idealism and altruism, by which I mean that they would share in, support, and be motivated by the goals of the researchers."); Wertheimer \& Miller, supra note 51, at 389 (speculating that some object to payment in research because "it will wrongly commodify a practice that should be based on altruism"). In a seminal article on payment incentives, Ruth Grant and Jeremy Sugarman also observe that "[i]t is important to do some things for the right reasons, and money is not always one of those reasons." Ruth W. Grant \& Jeremy Sugarman, Ethics in Human Subjects Research: Do Incentives Matter?, 29 J. MED. \& PHIL. 717, 728 (2004). However, Grant and Sugarman see payment incentives as potentially troubling not because they destroy deliberative insulation, but instead because they may lead to certain bad consequences, such as harms to child welfare, the degrading treatment of individuals, and the loss of "collective respect for personal dignity in the nature." Id. at 730 . Because this objection focuses on consequences rather than a conceptual connection, its validity is empirically testable.

83 Laura A. Siminoff, Money and the Research Subject: A Comment on Grady, 1 AM. J. BioETHICS 65, 66 (2001). 
of prohibiting payments need not be to paternalistically protect patients who want payments from deciding for the wrong reasons, but rather to protect patients who want deliberative insulation from being confronted with financial motivations. Nonetheless, her objection-understood as making the case that concerns about deliberative diversion simply are not important enough to justify prohibitions on payment-has force.

\section{B. Other Patient-Focused Concerns}

\section{Exploitation}

There is an ample literature on exploitation in healthrelated financial transactions, much of which comes from the literature on clinical research ethics. Unlike the concerns discussed in the previous Section, exploitation concerns are not about problems with the payment recipient's deliberation, but instead about an unfair distribution of the gains from a transaction. If an insurer pays a patient a small sum to select a cheaper treatment and profits enormously from the patient's choice, the payment may appear to constitute exploitation. This judgment can be intensified if the insurer's ability to profit is contingent on the patient's vulnerability-for instance, if the insurer is able to persuade the patient using only a small sum because the patient is very badly off financially. As Alan Wertheimer observes, exploitation can be mutually beneficial in comparison to no interaction at all: In the above example, the impoverished patient and the insurer both gain from the transaction, even though the patient gains much less. ${ }^{84}$ For this reason, exploitation is also distinct from coercion.

The fundamental challenge for exploitation arguments is to identify the criteria for non-exploitative transactions. Equal division of the social surplus from an interaction is not compelling, because many non-exploitative exchanges (for instance, paying a low price for a life-saving antibiotic) do not divide the surplus from the exchange equally: Instead, a large amount of the surplus from the trade goes to one side. ${ }^{85}$ Another criterion, that neither party profits from the other's vulnerability, is also not compelling-many health professions would not be profitable, or indeed financially tenable, if people were invulnerable to ill health. It is more compelling to argue that no one should profit unfairly from another's vulnerability,

Alan Wertheimer, Rethinking the Ethics of Clinical Research: Widening THE LENS 201 (2010).

85 Matt Zwolinski \& Alan Wertheimer, Exploitation, in ThE STANFord ENCYCLOPEDIA OF PHILOSOPHY (Edward N. Zalta ed.), http:/plato.stanford.edu/archives/fall2016/entries/exploitation/ [http://perma.cc/UJP4-VLYK]. 
but this returns us to the question of which profits are unfair. Wertheimer suggested that a hypothetically fair market is one sort of baseline, though it can be difficult to conceive of what a hypothetically fair market would be for some sorts of goods. ${ }^{86}$

Meanwhile, Matt Zwolinski has suggested a theory where mutually advantageous and consensual transactions should not be prohibited, regardless of how vulnerable any participant is or how the surplus from the transaction is divided. 87 Zwolinski's view of exploitation faces two objections. First, sometimes a transaction generates a relationship that produces new, non-waivable rights. For instance, even if A prefers to marry $B$ under terms that require $A$ to agree to a very unequal share of the benefits of marriage than not to marry $B$ at all, it may still be disallowed for B to marry A under those terms because marriage generates a right to a fair share of marital benefits. ${ }^{88}$ Even though this non-waivable entitlement leaves $\mathrm{A}$ worse off, it may simply be a feature of certain relationships. Second, sometimes the alternative to unequal division of benefits is not the absence of a transaction, but rather a transaction on more equal terms. Under these circumstances, it may be appropriate to prohibit or regulate transactions in order to encourage more equal transactions. Alex John London makes this argument regarding research ethics: If clinical trials are geographically mobile, while potential beneficiaries are not, trials can place the beneficiaries in an "auction" where the benefits are bid down to the minimum level required for the transaction to be mutually advantageous. By requiring a minimum level of benefit, an equilibrium may be reached that is better for all beneficiaries. ${ }^{89}$ Determining whether this objection applies will require both an empirical analysis of the benefits of regulation or prohibition and a conceptual analysis of whether the beneficiaries are entitled to that benefit.

In the end, exploitation considerations rarely justify prohibitions on paying patients. Under some circumstances, they justify prohibiting both the payment and the arrangement paid for entirely (as in the marriage case); but more often, they require only that patients be paid a minimum amount or that payments be regulated in some other way.

WERTHEIMER, supra note 84, at 209.

87 Matt Zwolinski, The Ethics of Price Gouging, 18 Bus. EtHICs Q. 347, 357 (2008).

88 Alan WERTHEIMER, EXPLOITATION 291 (1999).

89 Alex John London \& Kevin J.S. Zollman, Research at the Auction Block, 40 Hastings CTR. ReP. 34 (2010); see also Efthymios Athanasiou, Alex John London \& Kevin J.S. Zollman, Dignity and the Value of Rejecting Profitable but Insulting Offers, 124 MIND 409, 442-43 (2015) (describing a situation in which beneficiaries prefer to coordinate in order to avoid being faced with exploitative offers). 


\section{Disrespect}

Some offers of payment to patients may be criticized on the grounds that they communicate disrespect or insult. They may communicate disrespect because they suggest a paternalistic motivation on the part of the payer-that the payer is paying the patient to achieve an outcome because she believes she knows better than the payer what is good for her. ${ }^{90}$ Along similar lines, they may communicate disrespect because they suggest a failure to take the patient's commitments seriously. If a patient refuses to accept a prescription for a more costeffective treatment, following up that refusal with an offer to pay the patient to use the more cost-effective option may seem disrespectful of the patient's stated values. ${ }^{91}$ Neal Dickert provides an example: "Offering $\$ 50,000$ to a Jehovah's Witness to participate in a trial of a new blood product may not compromise autonomy or corrupt judgment, but it fails to recognize a constraint placed on the offerer by the values of the "offeree." 92 In response to concerns that Jehovah's Witnesses should be provided the opportunity to weigh their financial interests against their religious values, Dickert observes that

not to recognize that some offers are better not made, or that there are positions that persons would rather avoid based on their values (even if they may choose to take the offer if presented), seems simplistic. Due to the depth and nature of certain values, some offers can become indecent and disrespectful, and restraint can be a form of respecting holders of those values as autonomous agents. ${ }^{93}$

Scott D. Halpern, Kristin M. Madison \& Kevin G. Volpp, Patients as Mercenaries? The Ethics of Using Financial Incentives in the War on Unhealthy Behaviors, 2 CirCULATION 514, 515 (2009) ("Many people may be uncomfortable with incentive programs because they inherently imply that . . . people are making bad decisions, and that governments or employers that seek to change behaviors somehow know better."); Bernd Schubert \& Rachel Slater, Social Cash Transfers in Low-Income African Countries: Conditional or Unconditional?, 24 DEV. POLICY REV. 571, 576 (2006) ("Imposing conditions on people may smack of top-down attitudes of 'we know better' and 'the poor cannot be trusted")

91 Neal W. Dickert, Re-Examining Respect for Human Research Participants, 19 KENNEDY InST. ETHICS J. 311, 323 (2009) (suggesting that it is inappropriate to use payment to "influence people to participate in research studies to which it is known they would otherwise strongly object, based on important values or preferences").

$92 \quad I d$.

93 Id. at 324; see also Grant \& Sugarman, supra note 82 , at 728 ("To deliberately induce religious people to work on the sabbath by offering large incentives would involve an attempt to get them to act against what they see as their duties; it would be a form of bribery.") 
Dickert's example seems correct: It would be disrespectful to invite a nun to have sex, or to offer a rabbi thousands of dollars to join you at a crawfish boil, even if it is in principle possible that they would agree to the offer.

Offers of payment may also communicate disrespect because they appeal purely to the patient's economic interest and not to her other intellectual or rational faculties. Presenting money to someone rather than trying to convince her may appear to be a manipulative way of causing her to make a decision. Or, they may communicate disrespect because they leverage the payer's superior financial position, in the same way that throwing money at someone to get them to do something communicates disrespect.

Of course, what paying someone to do something expresses is highly context sensitive. It is rude to tip your host for cleaning up at a fancy dinner party to which you have been invited, but rude not to tip your server in a fancy restaurant. Accordingly, there is unlikely to be a general rule about when payment to patients is disrespectful. The important thing to remember is that patients are unlikely to be pure economic maximizers: rather, they are likely to view offers of money as appropriate in some contexts and inappropriate in others.

\section{Discrimination}

Jessica Roberts and Elizabeth Weeks Leonard have offered one of the most detailed discussions of whether consideration of health status is discriminatory. ${ }^{94}$ Their article initially identifies and brackets one answer to this question, namely that consideration of health status can "exacerbate existing inequalities based on other recognized categories," such as sex or race. ${ }^{95}$ They note that this strategy, adopted in Roberts' own earlier work, does not answer the question of whether health status is in itself an objectionable basis for advantages or disadvantages:

Concluding that lifestyle discrimination, at least with respect to nicotine use and obesity, is normatively wrong primarily because it has a disparate impact on historically disadvantaged populations, does not require Roberts to

Jessica L. Roberts \& Elizabeth Weeks Leonard, What Is (and Isn't) Healthism, 50 GA. L. REV. 833, 844 (2015) (considering "when [it is] normatively wrong to consider health status, and when [it is] normatively acceptable - perhaps even desirable").

95 Id. at 852 . I return below to the question of whether consideration of health status is objectionable because it has a disparate impact on the disadvantaged. 
recognize a new protected category for the unhealthy. From this perspective, healthism is simply a new form of discrimination against already protected (to varying degrees of scrutiny) groups. She does not actually have to decide whether health-status discrimination independently constitutes a normative wrong. Instead, she can operate from the presumption that racial, ethnic, and other types of discrimination are wrong and then add workplace policies against hiring nicotine users and overweight individuals to the list of ways that discrimination occurs. ${ }^{96}$

Roberts and Leonard then attempt to evaluate the claim that practices that treat individuals differently on the basis of health status "constitute their own independent normative wrong." 97 They conclude initially that the major antidiscrimination frameworks, in particular antisubordination (which protects historically oppressed groups from further disadvantage) and immutability (which regards unchangeable characteristics as inappropriate bases for advantages and disadvantages), do not obviously regard health status as an inappropriate basis for advantages and disadvantages. Individuals with specific health conditions are not necessarily a historically oppressed group, and health-related conduct-as well as health status - is not obviously immutable. In any event, immutability is a normatively dubious basis for regarding a characteristic as an inappropriate basis for a disadvantage, because some mutable characteristics-such as religion-are inappropriate bases for disadvantages, and some immutable characteristics—such as date of birth-can be appropriate bases for disadvantages.

However, Roberts and Leonard nonetheless conclude that considering health status is normatively objectionable if it:

1. Is driven by animus,

2. Stigmatizes individuals unfairly,

3. Punishes people for their private conduct,

4. Impedes access to health care,

5. Cuts off resources or otherwise limits the ability to adopt healthy life choices,

6. Produces worse health outcomes, or

7. Maintains or increases existing disparities. ${ }^{98}$ 
They conclude that "health-status distinctions that meet one or more of these criteria . . call for legal or policy intervention." 99

The most compelling criterion Roberts and Leonard discuss is animus. However, Roberts and Leonard define animus as "dislike or hostility towards the protected class of which that person is a member." 100 This definition is circular, because whether health status is a protected category is the very fact we are trying to determine. Second, dislike or hostility toward a class as such is not invariably objectionable - it is morally acceptable, and perhaps laudable, to dislike the "class of thieves" or the "class of bigots." A better, non-circular definition of animus would define it as dislike or hostility toward a class of individuals on the basis of a false or irrational belief. For instance, paying employees to attend HIV prevention sessions not because of concerns about the cost of health care for employees, but instead because the employer believes HIVinfected employees will infect customers they touch, would constitute animus. ${ }^{101}$

The other six criteria Roberts and Leonard list, however, are less compelling. Unfair stigmatization contains a normative component, namely unfairness, and is therefore circularclearly it is normatively objectionable to stigmatize people in an unfair (normatively objectionable) way, but which forms of stigma are unfair? Clearly animus-driven stigma is unfair, because animus is unfair, but it is unclear what the argument is against economically driven stigma-for instance, a wellness program that stigmatizes smoking in order to save on health care costs or reduce secondhand smoke in the workplace. Accordingly, unfair stigma has no independent significance.

$99 \quad I d$.

100 Id. at $886 \mathrm{n} .250$.

101 What counts as an irrational belief is a complex question I cannot hope to fully answer here. For instance, consider the example of a pharmacist who refuses to serve a gay person because of a deeply held belief that gay people are sinful and unclean. The pharmacist's refusal is not based on a scientific mistake in the way that the employer's decision is, but it also is not based on empirically verifiable or falsifiable claims. What weight to assign such judgments in a pluralistic society is a hotly debated question in both law and political philosophy. I am sympathetic to John Rawls's suggestion that decisions that affect others' basic rights must be justified using "reasons we might reasonably expect that they, as free and equal citizens, might reasonably also accept." John Rawls, The Idea of Public Reason Revisited, 64 U. CHI. L. REv. 765, 771 (1997); see also id. at 779 (explaining that a prohibition of same-sex marriage based purely on "religious or comprehensive moral doctrine," without appealing to generally accessible evidence, would be improper). Rawls's approach would disallow the pharmacist from denying others care based purely on his sincerely and deeply held religious convictions. Others, however, argue that sincerely and deeply held religious convictions can be a legitimate basis for limiting others' rights, even if we cannot reasonably believe that others could accept the bases for these convictions. See Christopher Eberle, Religious Convictions in Liberal POLITICS (2002). 
It is further unclear how far the concern about punishment for private conduct applies to payments. First, given the interconnectedness of health status, it is unclear which health behaviors properly count as private conduct. Second, the motivation for paying patients will not generally be punitive, but rather will be to encourage certain forms of behavior. Third, whether payments could be punitive even if we conceive of punishment merely as a disadvantage depends on what entitlement individuals have to payment-if individuals have no entitlement to be paid, not paying them, even for private conduct, will not count as punishment.

Meanwhile, payments to patients will not generally impede access to health care; and, furthermore, impeding access is sometimes acceptable. For instance, even if payments to nonsmokers make it more difficult for smokers to access health care, so long as smokers have reasonable access to health care, this outcome is not obviously wrong. The same point is true for cutting off resources.

Last, whether it is wrong to pay patients in ways that produce worse health outcomes or exacerbate existing disparities depends on who the actor making payments is. While governments may have a duty not to worsen health outcomes and to rectify disparities, it is less clear that private individuals have such a duty, particularly as concerns the rectification of disparities. For instance, even if paying employees or insured individuals to improve their health exacerbates certain economic disparities because unemployed or uninsured people are not paid, it is not obvious that employers or insurers have a duty to solve these disparities. Furthermore, returning to Roberts and Leonard's initial discussion of the connection between health status and identity-based discrimination, payments to patients can be designed in ways that do not have a disparate negative impact on individuals who are disadvantaged due to their sex, race, or other identity category. Payments to those with conditions disproportionately suffered by the already disadvantaged (for instance, payments for adherence to HIV) will help, rather than hurt, disadvantaged groups. Even payments that less often go to the disadvantaged, as might be the case with valuebased insurance payments incorporated into generous insurance plans, do not hurt the disadvantaged but rather fail to help them maximally. Unlike penalty programs such as increases in insurance premiums, payments to patients are unlikely to exacerbate the burdens that fall unfairly on individuals due to their identities.

\section{Commodification Concerns}

Concerns about commodification fundamentally take the 
position that money should not be a part of certain relationships, or should not be exchanged for certain other things. While commodification concerns have some overlap with deliberative worries, they are fundamentally concerns about money itself being in a place where it ought not be or playing a causal role it should not play, rather than about the ways in which money affects deliberation and motivation.

A classic article by Ruth Macklin concludes that "[p]ayment to patients to serve as research subjects is an ethically unacceptable commodification of research practice." 102 However, defining commodification is often challenging. The anthropologist Roberto Abadie asserts that

[o]ne of the most important critiques of the
pharmaceutical industry and the
commodification of bodies in trials research is
that the process not only exploits but
dehumanizes research subjects. The tendency of
research subjects to identify themselves with
guinea pigs conveys well this notion of
disembodied self. It is also not rare for volunteers
to resort to images of torture, sex work, or
prostitution when describing their activities. ${ }^{103}$

Abadie's objection to the "commodification of bodies" is not transparent to understand, but one plausible gloss is that people are seriously wronged when their bodies are used in certain ways (even with their agreement) for economic gain. Put more simply, it is wrong to trade health for money. 104 The basis for this objection, however, is less clear. Torture is wrong no matter whether the tortured party is paid for the torture. Whether sex work is wrong seems to be up for debate, and (following Yuracko 105) our concerns about individuals participating in sex work may not reflect objections to individuals using their bodies to earn money, but rather concerns that their doing so limits individuals' other capacities or the set of jobs available to others. We need more to be persuaded that trading health for money, or otherwise

102 Macklin, supra note 50 , at 3.

103 Roberto abadie, The Professional Guinea Pig: Big Pharma and the Risky World Of Human Subjects 10-11 (2010).

104 Similar concerns are raised in the environmental health literature-Kristin Shrader-Frechette describes the argument that "employees ought not to have to trade their health and well-being for higher wages" and that "paying people to put themselves at risk at work is not significantly different from murder for hire." Kristin Sharon Shrader-Frechette, Risky Business: Nuclear Workers, Ethics, and the Market-Efficiency Argument, 7 ETHICs \& ENV'T 1, 3-4 (2002).

105 See Yuracko, supra note 76. 
conditioning someone's access to money on their health status, is wrong.

Some arguments in defense of paying people to use their bodies in clinical research use the case of payment in employment as an analogy, reasoning that because payment is acceptable in employment, it is acceptable in clinical research. Christine Grady and Neal Dickert, for instance, respond to Marx Wartofsky's analogy between paid clinical research and prostitution, in which he argues that "one's body is not an appropriate 'commodity' for use in research," 106 by observing that this objection would also apply to many other forms of employment:

Providing incentives for any service involves, to some extent, "commodifying" people. Paying for research participation and the accompanying risks does not seem inherently different from many other paid transactions accepted as normal parts of life. Modeling, sports, police work, and firefighting, for example, all involve the use of human bodies, and some entail significant risk. ${ }^{107}$

Emily Largent similarly argues that "[r]esearch participation is appropriately analogised to unskilled, yet essential labour. In the context of unskilled labour people are generally permitted to sell their bodily services, even when that exposes them to risks." 108

However, it could instead be argued that because paying human subjects to put their health at risk in clinical research is morally objectionable, paying employees to put their health at risk is also objectionable. For this reason, Scott Halpern correctly observes that the persuasiveness of these "consistency arguments" is limited. He provides two additional reasons to reject commodification arguments: (1) first, that payment for health risks is not objectionable when neither the risks nor the payments are individually objectionable, and (2) that the payments would not raise concerns if they were provided to the

Dickert \& Grady, supra note 68 , at 391

Id.

Emily Largent, For Love and Money: The Need to Rethink Benefits in HIV Cure Studies, 43 J. MED. ETHICs 96, 99 (2017); see also Scott D. Halpern, Financial Incentives for Research Participation: Empirical Questions, Available Answers and the Burden of Further Proof, 342 AM. J. MED. SCI. 290, 292 (2011) ("Claims that financial incentives for research participation are wrong because of their degradation of the body fail simple tests of consistency, as it seems difficult to argue that they are unacceptable while we go on paying people for other more risky social services such as fire fighting, coal mining or military service."). 
wealthy. 109 The first argument is unconvincing: Many activities, such as drinking and driving, are bad in combination but not bad individually. The second is somewhat more persuasive; however, some might object to allowing even wealthy people to sacrifice their health in exchange for money.

Ultimately, the most persuasive response to commodification concerns would assert that individuals may voluntarily choose to entangle their health with their financial interests and that there is no obvious reason to be concerned about such transactions in themselves when the individual's consent appears valid. Of course, there may be persuasive reasons to worry about the impact on third parties or on society more generally - a concern discussed later-but it is doubtful that we should prevent people from trading their health for money for their own sake. Alex Rajczi discusses this argument in the research context:

[Some] will say that allowing [risky clinical research in which subjects participate for financial reasons] encourages people to gamble their health for money, and that it's wrong to try to get people to trade their health for money, no matter how much is being paid. I feel some sympathy for this position, but I think it cannot be maintained ... . [T] he principal reason for my view is that I cannot find any theoretical basis for forbidding the offer. ${ }^{110}$

Rajczi goes on to consider various theoretical reasons for concern, such as coercion, deception, and exploitation, and concludes that they do not apply. He also observes that the research subject's decision to participate accords with her considered judgment. For this reason, he concludes that the offer is allowable. The same seems plausible for many cases of health-consuming or otherwise health-involving employment. Ultimately, as Martin Wilkinson and Andrew Moore suggest, the most enduring basis for commodification concerns (understood as distinct from other concerns) involves a perfectionist ideal of social relations on which some things simply are not traded for others; such an ideal is not internally inconsistent, but is difficult to justify as a standard for permitting and prohibiting conduct. ${ }^{111}$

109 Halpern, supra note 108 , at 292.

110 Alex Rajczi, Making Risk-Benefit Assessments of Medical Research Protocols, 32 J. L. MED. \& ETHICS 338, 344 (2004).

111 Martin Wilkinson \& Andrew Moore, Inducements Revisited, 13 BIOETHICS 114, 127 (1999). 


\section{Societal Concerns}

\section{Absolute and Comparative Deservingness}

A major source of concern about payments for adherence, and to a lesser extent about payments for medical outcomes, is that they are unfair to patients who are not paid. The concern is that if the behavior being paid for is in principle under individuals' control, we are (1) paying people to do what they ought to do anyway or (2) paying the undeserving more than we pay the deserving. I categorize the first concern as one about absolute deservingness and the second as being about comparative deservingness.

Several discussions of programs to pay patients for adherence or outcomes raise concerns about absolute deservingness. For instance, Promberger et al. discussed the potential judgment that "bad behaviour should not be rewarded" as a reason for rejecting some incentive programs. ${ }^{112}$ Humphreys et al. note that "paying patients to attain specific outcomes can run into resistance by the public and sometimes care providers as well, usually expressed in words to the effect that 'they ought to change for free like everyone else' or 'why should we give goodies to baddies?" 113 Similarly, some patients and providers objected to a financial incentive for patients to reduce their injectable opioid treatments on the basis that the patients "should be doing this anyway." ${ }^{114}$ A study of New York Times comments by Park et al. categorized $21 \%$ of comments as raising the concern that "[f]inancial incentives reward people for irresponsibility for which they should face the consequences." 115 This concern has been substantiated in practice: attendees at an addiction treatment conference stated that "there is still some resistance in the treatment field to the use of incentives for behaviors such as attendance at treatment

112 Promberger, supra note 60, at 682-687; see also Theresa M. Marteau, Richard E. Asheroft \& Adam Oliver, Using Financial Incentives to Achieve Healthy Behavior, 338 BMJ b1415 (2009).

113 Keith Humphreys \& A. Thomas McLellan, A Policy-Oriented Review of Strategies For Improving the Outcomes of Services for Substance Use Disorder Patients, 106 ADDICTION 2058, 2063 (2011).

114 Joanne Neale, Charlotte N.E. Tompkins \& John Strang, Qualitative Evaluation of a Novel Contingency Management-Related Intervention for Patients Receiving Supervised Injectable Opioid Treatment, 111 ADdICTION 665, 669 (2015); see also Dana Mackin, Christopher Martin \& Jill K. MeGavin, Response: An Insidious Dependence, 4 ADDICTION SCI. \& Clinical PRAC. 16, 18 (2007) ("[W]e run into the same old political arguments: 'You're rewarding clients for things that they're supposed to do anyway."'); Nancy M. Petry, Contingency Management Treatments: Controversies and Challenges, 105 ADDICTION 1507, 1507 (2010) (discussing the concern that it is "unethical to pay people for what they should be doing anyway").

115 James D. Park et al., The New York Times Readers' Opinions About Paying People to Take Their Medicine, 39 Health Educ. \& BEHAV. 725, 728 (2012). 
and abstinence from alcohol and drugs. The resistance is in part due to philosophical opposition to rewarding substance abusers for something they should be doing anyway . . . " ${ }^{116} \mathrm{~A}$ British survey reported similar comments from public health officers when considering a proposal to pay women to breastfeed. ${ }^{117}$

Concerns about comparative deservingness are also frequently raised by providers and laypeople in discussions of payment for adherence. For instance, a plurality of lay respondents to one survey about the appropriateness of paying for smoking cessation worried that "[p]aying smokers to quit is not fair to non-smokers." ${ }^{118}$ A study of providing incentives to injectable drug users to attend HIV prevention workshops noted the objection that because "other groups do not seem to need incentives," "it is unfair to provide them only to some groups." ${ }^{119}$ The Park et al. study found that $10 \%$ of commenters worried that "[f]inancial incentives indirectly penalize people who have good health habits." ${ }^{20}$

The normative merit of these concerns, however, is dubious. It is neither required nor prohibited to pay people for doing what they ought to do, nor is it obviously wrong to pay some people and not others for doing the same thing. As Deren et al. point out, "[t]he belief that some high-risk groups may be more motivated to attend intervention sessions without incentives does not necessarily indicate that it is therefore inappropriate to use incentives for people or groups who may be less motivated." ${ }^{121}$ Another article makes a similar point:

Is it fair to withhold money from other service users, who have made the decision to stay adherent to their depot injection without any

116 James R. McKay et al., Extending the Benefits of Addiction Treatment: Practical Strategies for Continuing Care and Recovery, 36 J. SUBSTANCE ABUSE TREATMENT 127, 128 (2009).

117 Barbara Whelan et al., Healthcare Providers' Views on the Acceptability of Financial Incentives for Breastfeeding: A Qualitative Study, 14 BMC PREGNANCY \& CHILDBIRTH 1, 4 (2014) ("I think people should do things for the sake of their health and the wellbeing of their children so I don't like the idea of paying people to do what's good for them to do anyway.").

118 Long, Helweg-Larsen \& Volpp, supra note 48, at 1651; see also Halpern, Madison \& Volpp, supra note 90, at 515 ("[S]ome may consider it unfair to pay Peter to accomplish something that Paul does for free."); Karsten Lunze \& Michael K. Paasche-Orlow, Financial Incentives for Healthy Behavior: Ethical Safeguards for Behavioral Economics, 44 AM. J. Preventive Med. 659 , 662 (2013) ("Incentive programs aiming at behavior change might be unfair to those who already behave in a healthy way, in cases where programs reward only those with unhealthy behaviors ....").

119 Sherry Deren et al., The Impact of Providing Incentives for Attendance at AIDS Prevention Sessions, 109 PUB. HEALTH REP. 548, 553 (1994).

120 Park et al., supra note 115 , at 728.

121 Deren et al., supra note 119, at 553. 
incentive (and who, as a consequence, then might ask for that money as well)? If we think of [payments to patients] as remuneration for the effort, pain and possible side effects that the service user has from long-term depot injections, then this is probably unfair to more compliant users. However, if we think about this as an incentive for adherence, merely tilting the balance of an individual's informed decisionmaking process (much in the way as it happens with more informal gratification) towards drug adherence, person-centred incentives would not necessarily be unfair, as they (like the benefit system) merely take into account that some people need more positive reinforcement to succeed than others . . . . ${ }^{122}$

While paying people who are thought more likely to be nonadherent for adherence means that economic rewards do not necessarily track virtuous moral character, the notion that virtuous character entitles people to economic rewards is a dubious one, endorsed neither by theorists of distributive justice nor by economists. ${ }^{123}$ As Claassen states, the main purpose of payment incentives is to help the health care system achieve its preferred outcomes-while payment incentives could be designed to reward virtue and punish vice, they need not do so. It is similarly mistaken to claim that it is in general "unfair to pay people different amounts of money for performing the same activities." ${ }^{124}$ What people should be paid depends on what they will do if not paid and whether paying them a given amount will effectively achieve the payer's goal. While a payer is certainly permitted to endorse the principle that people should be paid the same amount if they do the same thing, the choice to pay patients does not involve a commitment to any specific vision about the goals of health care or health policy. Rather, payments to patients could be used in service of a variety of reasonable health policy goals.

Another objection contends that paying people to be adherent will incentivize people who would have been adherent in the absence of payment to change their behavior in order to receive incentives. ${ }^{125}$ This is largely an empirical question and

122 Dirk Claassen, Financial Incentives for Antipsychotic Depot Medication: Ethical Issues, 33 J. MED. ЕтHП 189, 192 (2007).

123 See Elizabeth Anderson, Thomas Paine's "Agrarian Justice" and the Origins of Social Insurance, in TEN NEgLeCted Classics of Philosophy 55, 75-76 (Eric Schliesser ed., 2016).

124 David B. Resnik, Bioethical Issues in Providing Financial Incentives to Research Participants, 5 MedicolegaL \& Bioethics 35, 39 (2015).

125 E.g., Joanne Shaw, Is It Acceptable for People to Be Paid to Adhere to 
involves considering two important factors. First, to answer the question, one must analyze how likely people actually are to change their behavior in order to become eligible for incentives. Even though providing incentives to drug addicts could in principle encourage non-addicts to become addicted in order to obtain incentives, the other disadvantages of becoming addicted are likely to prevent this form of incentive-seeking. So long as eligibility is based on a well-designed criterion rather than a pure self-report, incentive-seeking is unlikely to be a problem. ${ }^{126}$ Second, the answer to the empirical question depends on the cost of alternative methods of encouraging adherence or otherwise encouraging good outcomes. Even if there is some economic inefficiency in paying patients to be adherent (because some patients will seek to become eligible for incentives, and some patients who receive incentives would have done what they are being paid to do even in the absence of payment), paying for adherence will often still be the most effective way, all things considered, to improve outcomes. ${ }^{127}$

\section{Effects on Others' Options}

The option of being paid to make medical decisions, even if desired by some patients, may be worse for others. Building on an example of Yuracko's, if some chemistry professors are allowed to work as sexy chemistry professors, they may draw students away from ordinary chemistry classes, thus diminishing the demand for chemistry teaching positions that are not sex-plus positions. ${ }^{128}$ Similarly, patients who are willing to accept financial incentives do not merely receive compensation, but also affect the health care system in ways that may reduce the opportunities for workers unwilling to receive incentives. For instance, if financial incentives become predominant as a mode of reducing dependence on opioids,

Medication? No, 335 BRIT. MED. J. 233, 233 (2007) ("Paying for adherence, whether in the form of cash or non-financial benefits, creates all the wrong incentives because we cannot screen out people who would adhere anyway. By introducing payment, voluntary adherence will disappear. Why should patients agree to take medicines for nothing if they can be paid?"); George Szmukler, Financial Incentives for Patients in the Treatment of Psychosis, 35 J. MED. ETHICs 224, 227 (2009) ("The question of fairness is even more strongly at issue under a scheme where only those unlikely to comply with medication would be offered [incentives]. Why should patients who decide to take medication be penalised for a prudent choice? Perhaps many patients, content to take medication, would be tempted to say they would not, in order to receive the inducement.").

126 Kevin G. Volpp et al., P4P4P: An Agenda for Research On Pay-ForPerformance For Patients, 28 HeALTh AFF. 206, 209 (2009) ("Another issue is the need for precise targeting so that incentive programs do not largely reward people for doing 'what they would have done anyway."').

127 Robertson, supra note 45, at 921-22.

128 Cf. Yuracko, supra note 76, at 202-03. 
patients who prefer other methods of reducing dependence, such as psychological counseling, may find their options reduced.

Furthermore, the existence of the option of being paid can lead to pressure to take that option. Rather than offering unconditional aid, private individuals or public programs may ask patients to seek out payment incentives first. Debra Satz discusses this concern in regard to payment for organs, noting that if payment for organs is permitted, organs could become a requirement as collateral for loans, or individuals could be required to sell their organs prior to becoming eligible for public assistance. ${ }^{129}$

\section{Creating Corrosive Disadvantages}

Payments to patients may further be objectionable because they make inequality more significant. Consider the cases of inclusive shared savings or Robertson's "split benefit" proposal. ${ }^{130}$ If there is no economic reward for choosing a more cost-effective treatment, then both wealthy and poor patients may be equally likely to select a given treatment. In contrast, if there is an economic reward, then wealthy patients may be more likely to pay extra for a less cost-effective but marginally more effective (or no more effective) brand-name medication, while poorer patients may uniformly opt for the more costeffective generic. Certain medical services may become markers of economic status, just as consumer goods are now. To borrow from Jonathan Wolff and Avner de-Shalit's framework, payments to patients can turn economic status into a "corrosive disadvantage," where having less money not only means that a patient ends up with consumer goods that are less desirable, but also that the patient ends up with less desirable health care. ${ }^{131}$

This objection is complicated to assess. Unconditional economic transfers, or universal social programs that deliver most of their benefits to the least advantaged, can achieve societal gains without singling out people by economic status. However, these unconditional programs could potentially involve much higher costs. Furthermore, if private purchase of a good is permitted, wealthier patients may opt out of even unconditional programs (in the way that private hospitals might co-exist with a public system). Unless we combine a universal guarantee with a prohibition on going outside that guarantee, it is difficult to prevent economic status from

Debra Satz, The Moral Limits of Markets: The Case of Human Kidneys, 108 Proc. ARISTOTELIAN SOC'Y 269, 286 (2008).

130 See Robertson, supra note 45 , at 944-46

131 JoNATHan WolfF \& AvNER DE-Shalit, DisadVANTAGE 133-34 (2007). 
affecting individuals' access to health care or their consumption of health care resources. Furthermore, it is doubtful that payments to patients genuinely convert economic status into a corrosive disadvantage. Returning to Wolff and de-Shalit's framework, these payments may instead allow economically disadvantaged individuals to narrow their overall disadvantage-rather than having equally good health care but a very poor economic position, a patient may prefer to accept different (and slightly worse) care in exchange for a better overall economic position.

\section{Inefficiency}

There are a variety of reasons we might worry that paying patients to achieve certain outcomes is inefficient. One is that, under some circumstances, simply improving patients' economic circumstances may be more effective at achieving good health outcomes than paying patients to achieve those outcomes. ${ }^{132}$ Another is the worry that paying patients may undermine their long-term motivation to do the activities they were being paid to do previously. ${ }^{133}$ This concern is termed "crowding out" in the social-scientific literature. However, there is some evidence that crowding out is less likely where health-related behaviors are concerned. ${ }^{134} \mathrm{~A}$ third is that payments may simply be too expensive relative to the benefits produced.

These are all ultimately empirical questions, which can be assessed through social-scientific research. Rather than speculating about the likely outcome of that research, I only note here that these efficiency accounts presuppose some background theory of fair distribution on which-even if other factors also matter-total societal welfare plays a major role. The relative importance of total welfare compared to other values will determine the place that efficiency considerations should have in our evaluations.

\section{Paying Patients: Normative Categories and FRAMEWORKS}

132 Lucie Cluver \& Lorraine Sherr, Cash Transfers-Magic Bullet or Fundamental Ingredient?, 4 LANCET GLOBAL HEALTH e883, e884 (2016) ("The infrastructure and cost of policing the conditions reduces reach to individuals at highest risk. The clear lessons from this study are that conditionality does not substantially advance the cause ....").

133 E.g., Bruno S. Frey \& Reto Jegen, Motivation Crowding Theory, 15 J. ECoN. SURVEYs 589, 596-97 (2001).

134 Marianne Promberger \& Theresa M. Marteau, When Do Financial Incentives Reduce Intrinsic Motivation? Comparing Behaviors Studied in Psychological and Economic Literatures, 32 HEALTH PSYCHOL. 950, 955-56 (2013). 
Assessing the concerns that have been raised about payment to patients suggests that such payments merit neither blanket disapproval nor blanket disapprobation. Rather, determining when these payments are appropriate requires a nuanced weighing of their advantages against their disadvantages. I turn now to the question of when-in light of the concerns identified above-payments to patients should be regarded as normatively appropriate or inappropriate. Currently, payments are frequently categorized by their factual context-for instance, they are grouped into payments for smoking cessation, research participation, or medication adherence. A better system would look to the rights and duties of the actors making payments to patients and how the payments affect these actors and their relationships with patients. In this Part, I consider three salient categories of such actors: "micro-level" actors like providers; "meso-level" actors like insurers and hospitals; and "macro-level" actors such as governments. ${ }^{135}$

\section{A. Providers}

Payments to patients - both by providers and by otherscan affect providers in a variety of ways. Providers who pay patients to use their services spend some money up front to increase use of services, potentially leading to greater revenues down the line. Meanwhile, providers who pay for adherence can improve the efficacy of providers' treatment efforts, allowing providers to treat patients more quickly and efficiently. Payments by actors other than providers can also affect providers: insurers and governments who pay patients to decline services can hurt providers' bottom line, while payments to use certain services (such as screening or family planning services) can increase utilization of some providers' services.

In this Section, I focus on how payment might affect the provider-patient relationship and providers' obligations to patients. I focus on the physician-patient relationship, though I recognize that there are a variety of other providers, such as nurses, physician assistants, and medical paraprofessionals.

Ezekiel and Linda Emanuel suggest four models for the physician-patient relationship: paternalistic, informative, interpretive, and deliberative. ${ }^{136}$ Each model will be affected in different ways by payments to patients.

First, "[i]n the paternalistic model, the physician acts as the

135 For this terminology, I draw partially on Note, Scarce Medical Resources, 69 COLUM. L. REV. 620 (1969).

136 Ezekiel J. Emanuel \& Linda L. Emanuel, Four Models of the PhysicianPatient Relationship, 267 JAMA 2221, 2221-22 (1992). 
patient's guardian, articulating and implementing what is best for the patient." 137 On this model, physicians and other similar providers would be free to provide incentives whenever they think doing so would be good for the patient, regardless of the patient's autonomous preference. However, incentives may be unnecessary, given the power of the physician simply to implement the care program that she judges best: "At the extreme, the physician authoritatively informs the patient when the intervention will be initiated." ${ }^{138}$ Because this model puts less of an emphasis on patients' autonomous decisions, concerns that payments constitute coercion or undue inducement, or that they divert patients from proper deliberation, do not apply. However, there could still be concerns about payments to patients that make the patients worse off by communicating disrespect or undermining patients' intrinsic motivations.

Second, in the informative model, "the objective of the physician-patient interaction is for the physician to provide the patient with all relevant information, for the patient to select the medical interventions that he or she wants, and for the physician to execute the selected interventions." 139 This model leaves little room for the use of incentives, since the patient is presumed to arrive with well-formed preferences to which the provider should defer-the only room for provider intervention will be sharing information about available interventions and their consequences. In particular, this model will reject payment incentives that interfere with patients' autonomous decisions regarding treatment.

Third, the interpretive model sees the physician as a "counselor, analogous to a cabinet minister's advisory role to a head of state, supplying relevant information, helping to elucidate values, and suggesting what medical interventions realize these values." 140 This model allows more room for payment incentives, insofar as they may help a patient overcome weakness of will in order to better realize his or her core values.

Last, Emanuel and Emanuel endorse the deliberative model. In this model, "the physician acts as a teacher or friend, engaging the patient in dialogue on what course of action would be best." ${ }^{141}$ Furthermore, "[n]ot only does the physician indicate what the patient could do, but, knowing the patient and wishing what is best, the physician indicates what the patient should do, what decision regarding medical therapy

137 Id. at 2221.

138 Id.

139 Id.

140 Id. at 2223.

141 Id. 
would be admirable." 142 The deliberative model assumes that physicians have or can gain access to privileged knowledge about which medical decisions are morally admirable. In this way, the deliberative model is like the paternalistic model. However, the deliberative model makes more of an effort to alter the patient's deliberation than the paternalistic model does. While the paternalist simply ignores the patient's requests when they diverge from what is medically best according to an objective criterion, the deliberative physician attempts to get the patient to request what is medically best. It is not clear what the deliberative model counsels in cases where patients are not persuaded: Emanuel and Emanuel claim that "the physician aims at no more than moral persuasion: ultimately, coercion is avoided, and the patient must define his or her life and select the ordering of values to be espoused." 143

Of these models, the deliberative model should be the friendliest to payment incentives. However, payment incentives are consistent with the deliberative model only when they promote deliberation between patient and physician. If incentives serve to make patients suspicious of physicians' commitment to help, or if incentives are so large that they foreclose the relevance of the patient's health, they will be inconsistent with the deliberative model. The deliberative model is likely to be friendly to inclusive shared-savings payments, given the model's emphasis on the importance of encouraging the patient to do what is in the public interest, ${ }^{144}$ and will also be favorable to payments for adherence that serve to encourage patients to deliberate.

\section{B. Insurers and Hospitals}

Unlike direct health care providers such as physicians and nurses, "meso-level" actors like hospitals and insurers are not governed by a specific code of professional ethics, nor do they stand in a close relationship to patients. Accordingly, a more applicable model for these actors comes from business ethics. Joseph Heath has suggested a "market failures approach" to business ethics, on which businesses have a duty not to exploit failures in markets. ${ }^{145}$ Heath suggests that businesses have a moral permission to seek profits because (in a perfectly competitive market) their profit-seeking will produce good outcomes, but concludes that this permission is granted by

$142 I d$.

143 Id.

144 See $i d$. (explaining that the deliberative model involves suggesting altruistic motivations to patients).

145 See Joseph Heath, Morality, Competition, and the Firm: The Market FAILURES APPROACH TO Business ETHICS (2014). 
society on the condition that businesses not exploit various market imperfections. Heath grants that some of these conditions may be too demanding in a context where other firms are not following them-for instance, if other firms are trying to create barriers to entry, it may be self-defeating not to do so as well. However, he suggests that these conditions still represent important guiding principles for business ethics.

Applying an account of business ethics to markets in health care and health insurance represents an important and complex project, in light of the numerous ways in which these markets diverge from competitive ideals. Business ethics principles could help to provide a better justification for an improved anti-kickback law and generally a better set of norms for when payment incentives from providers would be permitted. However, the task of developing these norms goes beyond this Article's scope.

\section{Governments}

Whether "macro-level" actors like governments should provide incentives will be contingent on the proper role of government, which is itself a topic of substantial debate. However, there are certain governmental goals that garner agreement across a wide variety of perspectives, such as the provision of public goods. ${ }^{146}$ Paying patients to achieve public goods, such as the prevention of infectious disease, is the sort of initiative that should garner broad support. In contrast, payments to patients that unduly induce them to take health risks, or that take advantage of patients' limited rationality in order to financially exploit them, should not be supported.

Government endorsement of certain incentives also raises distinctive questions about what government action expresses to patients and to others. ${ }^{147}$ Governmental decisions to pay patients may express disrespect for those patients, or for individuals who are not paid, in different ways than do private decisions. This suggests that governments should be particularly careful to ensure that their payments to patients do not, for instance, exacerbate disadvantages along identity-

146 See, e.g., Cabot Corp. v. United States, 694 F. Supp. 949, 957 (Ct. Int'l Trade 1988) ("Governments provide many such [public] goods and services because of the inability of the price system to effectively provide these goods, which tend to be indivisible and collectively consumable by all citizens whether they pay for them or not."); see also Liberty Univ., Inc. v. Geithner, 671 F.3d 391, 447 (4th Cir. 2011) (Davis, J., dissenting) ("[G]overnments are formed precisely to compel purchases of public goods.").

147 Cf. Elizabeth S. Anderson \& Richard H. Pildes, Expressive Theories of Law: A General Restatement, 148 U. PA. L. REV. 1503, 1520 (2000) ("Expressive theories of law are concerned with evaluating state action. On the rights and equality side of constitutional law, such theories assert that state action is required to express the appropriate attitudes toward persons."). 
based category lines.

\section{Private Individuals}

Private individuals enjoy the broadest permission to offer incentives to patients. Because patients stand in no particular relationship to private individuals, and private individuals have little power over individual patients, patients' options will typically not be seriously constrained by payment incentives offered by private individuals, and those incentives will also be easy to avoid. Accordingly, even if-for instance-it would be impermissible for governments, insurers, or doctors to pay patients to seek sterilization or not to have abortions, it will generally be permissible for private individuals to make these sorts of offers.

However, even if private individuals typically act permissibly in offering incentives, they may not always act admirably. As discussed above, certain offers may communicate insult or disrespect to others. When rapper Ralo "made it rain" on homeless people in an effort to help them, he was criticized for insulting his beneficiaries. One commentator summarized the effort:

"There may be better ways to have a profound impact, but it doesn't mean an impact wasn't made," said John Moeller, the executive director of Action Ministries, which houses and feeds homeless families in Atlanta. "I'm of the belief that if there's one person trying to do some good in the world, we should encourage that. I celebrate the generosity that was offered up. Maybe the process he used could have been better." 148

If we imagine a public health version of Ralo-one who decided to shower dollar bills on program participants leaving a HIV education meeting or a class on prenatal nutrition-we can see a similar ambivalence. Even though offering these incentives in these ways is permissible, it does not exemplify the best way of treating others. Offering a better alternative, however, is a highly contextual task.

Cleve R. Wootson, Jr., Why This Atlanta Rapper Tried to Make it Rain' on the Homeless, WASH. Post (Oct. 25, 2016), http://www.washingtonpost.com/news/arts-andentertainment/wp/2016/10/25/why-this-atlanta-rapper-tried-to-make-it-rainon-the-homeless/ [http://perma.cc/55NP-Y2JR] 


\section{Paying Patients: Legal Issues}

Paying patients further presents a variety of legal implementation issues. In this Part, I discuss a few such issues.

\section{A. Taxability and Program Eligibility}

Many concerns about payment to patients involve worries that patients are underpaid relative to the benefits they provide society. As such, it is important to consider not just the gross value of payments, but their net value once taxes and other consequences of earned income are taken into account. Such a considered approach involves assessing whether payments to patients will count as income for tax purposes and whether they will affect eligibility for means-tested social programs. ${ }^{149}$ The Internal Revenue Service (IRS) has been clear that incentive payments in wellness programs, as well as payments to participants in clinical research, constitute taxable income. ${ }^{150}$ (It is unclear, though, whether these payments should also be subject to self-employment taxes; the IRS has taken the position that whether they are hinges on whether "the participants are in a trade or business of participating in medical research studies." 151) However, employers and insurers do have the option of using discounts on insurance premiums, which would make an incentive nontaxable, rather than incentive payments. ${ }^{152}$ Clinical research facilities could potentially replace payments with discounts on their treatment charges, though this has not been described in

149 See Claassen et al., supra note 23 , at 6 ("Will the money received for medication have an impact on social and disability allowances?").

150 On wellness programs, see Memorandum from Stephen Tackney, Deputy Assistant Chief Counsel (Emp. Benefits), to Mark Ericson, Senior Att'y, Tax Treatment of Wellness Program Benefits and Employer Reimbursement of Premiums Provided Pre-tax Under a Section 125 Cafeteria Plan (Apr. 14, 2016), http://www.irs.gov/pub/irs-wd/201622031.pdf [http://perma.cc/H38H$\mathrm{K} 7 \mathrm{VX}]$; on clinical trials, see Indiana State University Guidelines for Compensation to Human Research Participants, IND. ST. U., http://www2.indstate.edu/controller/docs/ISU $\% 20$ Guidelines $\% 20$ for $\% 20 \mathrm{Comp}$ ensation \%20for\%20Research\%20Participation.pdf [http://perma.cc/2SW5WQHE], citing IRS Private Letter Ruling 9106004 (Aug. 2, 1990).

151 Memorandum from Janine Cook, Branch Chief, to Glenn DeLoreia, Acting Program Manager, Reporting SECA Payments Made to Medical Research

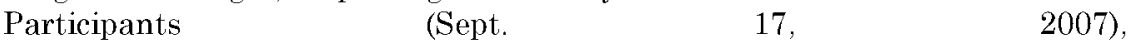
http://www.irs.gov/pub/lanoa/pmta01353_7356.pdf [http://perma.cc/Y56F. 2LAL].

152 See Kevin G. Volpp et al., Redesigning Employee Health Incentives-Lessons from Behavioral Economics, 365 NEW ENGL. J. MED. 388, 390 (2011) ("Providing rewards outside the premium framework would make them taxable, and it's unclear whether a taxed but more salient reward is more effective than a premium adjustment."). 
the literature. There is no literature on the taxability of various payments for adherence, such as the contingency management payments made to discourage addiction.

Another approach that has been used in designing government-provided incentives is to expressly exclude incentive payments from the income considered when determining eligibility for means-tested programs. Several provisions of the Affordable Care Act (ACA) as initially drafted did this, ${ }^{153}$ as did a provision of the Social Security Act that "provides for the income and resource exclusion of compensation received for participating in clinical trials researching and testing treatment of rare diseases or conditions." 154

\section{B. Antidiscrimination Law}

Another concern discussed above involves the charge that payments discriminate. Payments that favor the healthy over the unhealthy, or the disabled over the non-disabled, could not only be unethical but also be violations of law. Several federal statutes potentially apply to payments to patients, including the Americans with Disabilities Act (ADA), the Health Insurance Portability and Accountability Act (HIPAA), the Genetic Information Non-Discrimination Act (GINA), and the Affordable Care Act (ACA). ${ }^{155}$ The ADA and GINA regulate the request of medical information, whereas the ACA and HIPAA directly regulate insurers. Broadly speaking, the ACA and HIPAA are more permissive, whereas the ADA and GINA are more restrictive.

The ACA differentiates incentive payments into two categories, "participatory" (requiring only the performance of some behavior) and "health-contingent" (requiring the achievement of an outcome). Participatory incentives are less tightly regulated than health-contingent ones: The ACA permits

premium discounts, rebates, or other rewards not based on satisfying a health status factor-related

153 See 124 Stat. 564 (2010) ("Any incentives provided to a Medicaid beneficiary participating in a program described in subsection (a)(3) shall not be taken into account for purposes of determining the beneficiary's eligibility for, or amount of, benefits under the Medicaid program or any program funded in whole or in part with Federal funds.").

154 Social Security Program Operations Manual System, SI 00830.735 Payments for Clinical Trial Participation, Soc. SECURITY ADMIN., http://secure.ssa.gov/poms.nsf/Inx/0500830735 [http://perma.cc/X5W8UHNM].

155 Michelle R. Seares, Note, Wellness at Work: Reconciling the Affordable Care Act with the Americans with Disabilities Act, 84 GEO. WASH. L. REv. 218, 22425 (2016). 
standard as long as they are available to all similarly situated individuals. Thus, plans are permitted to reimburse costs for gym memberships or offer rewards for attending smoking cessation programs. In addition, the ACA permits rewards based on satisfaction of a health status factor-related standard if the program meets a series of requirements. Rewards may take many forms, including "a discount or rebate of a premium or contribution, a waiver of all or part of a cost sharing mechanism[,] . . . the absence of a surcharge, or the value of a benefit that would otherwise not be provided under the plan." A program involving a reward for maintaining a specified BMI or a penalty for those who use tobacco would be subject to these requirements. ${ }^{156}$

Notwithstanding these permissions, the Equal Employment Opportunity Commission has filed three lawsuits challenging large participatory incentives - even if compliant with the ACA - as violating the ADA. These incentive programs were framed as penalties rather than rewards, with employees who declined to participate in wellness programs being subject to charges. However, whether a program framed as a reward would violate the ADA is a complex question. A recent student note characterizes large incentives as coercive regardless of whether they represent a bonus or penalty, but-as I discuss in Part III-coercion is an inapt description of a program that offers benefits to which individuals are not entitled. ${ }^{157}$ A betterframed concern is that incentives for participatory programs violate the ADA insofar as they objectionably condition access to financial advantage on willingness to answer disabilityrelated questions, or similarly violate GINA with respect to genetics-related questions. However, many incentive programs do not target either genetic conditions or disabilities, but instead focus on other health problems. There is no obvious antidiscrimination bar to such programs.

State law represents another basis on which payments to patients might be categorized as discriminatory. Madison, Volpp, and Halpern note that "[a] number of states have enacted statutes that prohibit employers from discriminating against employees based on smoking outside the workplace, perhaps reflecting in part concerns about employers'

156 Madison, Volpp \& Halpern, supra note 49, at 462.

157 Seares, supra note 155, at 244; on coercion, see Madison, Volpp \& Halpern, supra note 49 , at $459-60$. 
interference in employees' personal lives." 158 Relevant issues for these statutes' potential application to financial incentives include whether these statutes apply to incentives as well as penalties and whether they apply to actors other than employers.

Matt Lamkin advances the related argument that programs that incentivize employees to make certain health care decisions, such as taking particular medications, violate informed consent because employees are faced with a choice between paying more for insurance or making health care decisions they would prefer not to make. ${ }^{159}$ But the fact that one stands to gain or lose much from a given decision cannot be enough to vitiate informed consent. For instance, if a taxi driver would lose his driver's license if he refused to get glasses, this would be a major incentive to make the health care decision to see an optometrist and spend money on glasses, but it would not vitiate informed consent.

\section{Anti-Kickback Statutes}

As Part I discussed, some payments to patients to purchase or use certain health care interventions may constitute illegal kickbacks. One recent article describes the purpose of the federal anti-kickback statute:

The statute incorporates the premise that because, generally, the more patients a medical provider sees, the more revenue the provider generates from federal health-care programs, like Medicare, then anything "given" to patients that makes them more likely to see the medical provider may be a prohibited kickback that could lead to criminal prosecution or civil monetary penalties. This kickback would potentially have the result of generating more fees for the medical provider, while concomitantly driving up the cost of federal health-care programs. ${ }^{160}$

Paying patients whose medical care is publicly funded to use that care may benefit patients, but also incentivizes the consumption of a public resource: because patients do not experience all-and in some cases do not experience any-of the cost of care, paying even small kickbacks could be an easy way to increase consumption. At least one justification for the 
statute is that conserving public resources is an important enough goal to justify prohibiting payment incentives.

However, it is normatively unclear that kickbacks to patients are objectionable, even in the cases of patients whose care is publicly funded. Kickbacks paid to actors other than the patient are objectionable for reasons other than resource conservation, since such kickbacks encourage these actors to put their financial interests above patients' medical interests. 161 In contrast, paying kickbacks to patients themselves does not raise a concern about dual loyalties, but only about resource conservation. If a kickback draws in patients who otherwise would not receive care and pays them money at the same time, the public treasury is being used to fund patient care (even if providers also profit from the increased use of their services at public expense). Meanwhile, if the kickback simply draws patients from other providers, then inter-provider competition to pay the most attractive kickback will merely serve to transfer money from providers to patients, with no net burden on the public treasury. Such kickbacks do not seem obviously more objectionable than, for instance, a college offering to match federally funded financial aid with its own private aid. While it may be objectionable for kickbacks, such as drug coupons for brand-name drugs, to lead patients to use expensive, non-beneficial care, a more effective way of limiting such care is to limit provider reimbursements for offering it, for instance by imposing formulary restrictions.

Concerns about kickbacks offered to patients should be even more attenuated when the patients are privately insured. Providers should not bill insurers for services patients never paid for, ${ }^{162}$ but it is not obvious that providers act wrongly by encouraging patients to spend private insurers' money freely. To the extent insurers want patients to curb their spending, they could compete with providers by offering shared-savings

161 Timothy Stoltzfus Jost \& Sharon Davies, The Fraud and Abuse Statute: Rationalizing or Rationalization?, 15 HEALTH AFF. 129, 129 (1996) (describing one "purpose for the bribe and kickback and self-referral laws" as being "to regulate conflicts of interest in the practice of medicine"); Aaron Chess Lichtman, Note, Commercial Exploitation of DNA and the Tort of Conversion: A Physician May Not Destroy A Patient's Interest in Her Body-Matter, 34 N.Y. L. SCH. L. REV. 531, 559 (1989) (arguing that anti-kickback rules "prevent physicians from using their positions of trust to induce their patient into giving them gifts, and from creating financial interests which may interfere with their complete loyalty to their patient").

162 See Aetna, Inc. v. Health Diagnostic Lab. Inc., No. CV 15-1868, 2016 WL 6070542 , at ${ }^{*} 5$ (E.D. Pa. Oct. 17, 2016) ("The routine waivers of patient copayments and coinsurance effectively afforded a discount to Aetna members from the amounts that the Aetna members would normally be billed . . . . The billed charges submitted to Aetna should have been reduced by the amount of the considerable co-payments and coinsurance amounts that had been waived, but the billed charges never accounted for those discounts."). 
payments along the lines Schmidt and Emanuel suggest ${ }^{163}$ patients could decide whether they prefer to accept the provider's preferred treatment and receive a kickback, or accept the insurer's preferred treatment and receive a shared savings payment. Such competition would be better for patients, though perhaps worse for insurers and providers. Federal courts have been reluctant to classify financial incentives to privately insured patients as illegal kickbacks, ${ }^{164}$ though some states have taken express measures to prohibit kickbacks to privately insured patients. ${ }^{165}$

\section{Contract Issues}

Payments to patients will in some cases involve contracts between patients and payers. These contracts could potentially be void on the basis of being against public policy, on the basis that the patients lacked the capacity to contract, or on some other basis. They could also be unenforceable. The public-policy concern connects with a variety of the normative concerns above, whereas the lack-of-capacity concern is more specific.

If patients are paid to harm their own health or otherwise diminish individual capacity, or if paying patients will clearly hurt the public health, the contract might be void for being against public policy-as allowed for under the laws of many states. ${ }^{166}$ Courts have held insurance policies that incentivized insureds not to report sexual misconduct (by reducing insurance payouts in cases that involved sexual misconduct) to be void as against public policy, because the prevention of sexual misconduct is an important public interest. ${ }^{167} \mathrm{~A}$ court also held a settlement agreement that prohibited the disclosure

163 See Schmidt \& Emanuel, supra note 40.

164 Am. Fed'n of State, Cty. \& Mun. Employees Dist. Council 37 Health \& Sec. Plan v. Bristol-Myers Squibb Co., 948 F. Supp. 2d 338, 352 (S.D.N.Y. 2013) (rejecting the view that the "use of co-pay subsidy cards-or the routine waiver of co-pay obligations in the context of private insurers-states a claim for health care fraud").

165 Andrew Grosso, Medical Necessity and the Medicare and Medicaid AntiKickback Statute, 40 FED. B. News \& J. 301, 306 (1993) ("Private insurance is not covered by any federal kickback statute. The responsibility to protect private insurance carriers falls to the states. Sometimes this protection takes the form of a criminal remedy, and sometimes it is limited to a professional sanction, such as suspension from the practice of medicine."); Jason M. Healy, William M. Altman \& Thomas C. Fox, Confidentiality of Health Care Provider Quality of Care Information, 40 BRANDEIS L.J. 595, 606 n.36 (2002) ("Some state anti-kickback statutes are broad enough to cover kickbacks without regard to the type of payor (e.g., Medicare, Medicaid, private insurance, or individual).").

166 E.g., Lesieur v. Inhabitants of Rumford, 93 A. 838, 839 (Me. 1915); LaPoint v. Richards, 403 P.2d 889, 895 (Wash. 1965).

167 Am. Home Ins. Co. v. Cohen, 815 F. Supp. 365 (W.D. Wash. 1993), aff'd 67 F.3d 305 (9th Cir. 1995). 
of physician misconduct to be void because it violated the public policy expressed in "a statute designed to protect public health by ensuring that medical staffs have full information in their hiring decisions." 168 Analogously, courts might potentially void a payment incentive contract if it encouraged conduct that was against the public interest-for instance, if it encouraged unhealthy behavior or the consumption of public resources.

Contracts might also be void if the patients agreeing to them lacked the mental capacity to contract. A Virginia case observes that habitually drunk individuals may lack that capacity:

[W]hen a person's habitual addiction to intoxication renders him extremely subject to imposition, such habits, though not carried to an excess constituting absolute incapacity, lay a ground for strict examination whether any instrument executed by him does not in itself, or in the attendant circumstances, contain evidence that advantage was taken of those habits. ${ }^{169}$

Similar concerns arise, for instance, if an incentive program for cocaine addicts involved a contract.

For many payments to patients, these contract issues can be avoided by using a unilateral contract that can only be accepted through performance, in which the incentive provider offers to pay if and only if the patient brings proof of having engaged in the desired behavior or having achieved the desired outcome. Unilateral contracts are frequently used where prizes or rewards are offered, ${ }^{170}$ and payments to clinical trial participants have been analyzed under a unilateral contract framework. ${ }^{171} \mathrm{~A}$ person who receives what they were promised in a unilateral contract can have no complaint. For instance, even if "bodily contract" clauses, where individuals forfeit benefits if their weight exceeds a certain amount, might be voidable, ${ }^{172}$ someone who is paid a certain amount for losing

Walton v. Jennings Cmty. Hosp., 875 F.2d 1317, 1323 (7th Cir. 1989).

169 Taliaferro v. Emery, 98 S.E. 627 (Va. 1919).

170 Melvin Eisenberg, Probability and Chance in Contract Law, 45 UCLA L. REv. 1005, 1041 (1998) ("IP|rizes and rewards have an important structural similarity: they are offers to pay for the performance of an act, normally by a member of the public, and therefore constitute prototypical unilateral contracts.").

171 Seema Shah \& Patricia Zettler, From a Constitutional Right to a Policy of Exceptions: Abigail Alliance and the Future of Access to Experimental Therapy, 10 Yale J. Health Pol'Y, L. \& Ethics 135, 154-55 (discussing Dahl v. HEM Pharm. Corp., 7 F.3d 1399 (9th Cir. 1993)).

172 See Veronica Colon-Padilla, Note, The "Miss America" Ideal: An Analysis of the Legality and Enforceability of Bodily Contract Clauses Within Modern Pageantry and the Gender and Cultural Implications of Using 
weight has no basis for challenging the incentive system. Glenn Cohen discusses an interesting unilateral contract case involving, in effect, an incentive concerning reproductive choices:

[A] Missouri case involving a father who disinherited his unwed pregnant daughter, but agreed to put her back in the will if she would terminate her pregnancy, which she did, actually found the contract enforceable notwithstanding that getting an abortion was the consideration. But the setting is unusual, and involved a unilateral contract that could only be accepted by performance, so in a real sense it could not be enforced against the daughter. ${ }^{173}$

As Cohen observes, the daughter was able to require the father to put her back in the will, but the daughter could not have taken the proffered incentive and then complained that the contract was unenforceable as against public policy, because she would have already done the act being incentivized. The only danger of the unilateral-contract model is that the possibility that the payer will attempt to back out of the offeron the basis that the offer he himself made is against public policy-may make the incentive less attractive.

\section{CONCLUSION}

Payments to patients raise numerous interesting issues, both legal and ethical. One contribution I hope to have made, regardless of whether readers agree with my normative conclusion, is to have provided a taxonomy and review of the terrain. In particular, it is important to distinguish conceptual questions about payments (such as whether they violate individuals' rights or prevent an ideal form of deliberation) from empirical questions (such as whether they weaken individuals' intrinsic motivation or whether the costs of administering them outweigh the benefits). It is also important to distinguish different types of normative concerns from one another and distinguish different actors who might provide incentives.

Despite the presence of normative concerns about payments to patients, I believe such systems deserve to be tried in

Governmentally Unregulated Weight Requirements, 34 WOMEN's RTS. L. REP. 79, $101(2012)$

173 I. Glenn Cohen, The Constitution and the Rights Not To Procreate, 60 STAN. L. REv. 1135, 1192 n.234 (2008) (citation omitted) (discussing L.G. v. F.G.H, 729 S.W.2d 634 (Mo. Ct. App. 1987)). 
practice. They have the potential to be cost-effective and efficacious (which studies have borne out), and they could be implemented quickly and flexibly. In environments where larger social programs are difficult to enact and where government actors are unresponsive, payments are easy for private and non-governmental actors to pilot. Concerns that payments, as opposed to penalties, coerce individuals are illfounded.

In thinking about where to start with payments to patients, the potential to benefit disadvantaged individuals must be balanced against the avoidance of harm. Beginning with small payments by private actors to patients who are experiencing only minor health problems and are otherwise well-off reduces the chance that payments would be undue inducements or would expose recipients to stigma or unforeseen disadvantages. An example might be an insurance company paying participants to select lower-cost allergy medications or treatments for indigestion. These sorts of payments are less likely to cause harm, but are also less likely to produce large benefits for patients or for society. In contrast, payments that are larger, come from state actors, or are received by patients who have major health problems - for instance, if Medicaid were to offer large payments for adherence to opioid treatment-increase the risk of undue inducement or stigma. However, the appeal of using payments in these more urgent contexts is that they could potentially generate large benefits for seriously disadvantaged individuals. Ultimately, outside of cases where patients are obviously unable to respond rationally to inducements, the use of payment incentives is a highly context-dependent decision. There is nothing conceptually unique about negative prices for health care: they represent part of a continuum of the incentives and reasons we might offer people to make health decisions, and one that deserves greater attention. 